\title{
Definition of Interaction Curves for the In-plane and Out-of-plane Capacity in Brick Masonry Walls
}

\author{
M. A. Najafgholipour ${ }^{1}$, M. R. Maheri $^{2 *}$ P. B. Lourenço ${ }^{3}$ \\ ${ }^{1} \mathrm{PhD}$ candidate, Department of Civil Engineering, Shiraz University, Shiraz, Iran, \\ ${ }^{2}$ Corresponding author, Professor of Civil Engineering, Shiraz University, Shiraz, Iran, \\ maheri@shirazu.ac.ir \\ ${ }^{3}$ Professor, ISISE, Department of Civil Engineering, University of Minho, Portugal
}

\begin{abstract}
During an earthquake a wall is subjected to a three dimensional acceleration field and undergoes simultaneous in-plane and out-of-plane loading. The action of one type of loading on the wall affects the strength of the wall against another type of loading. In this paper, a numerical investigation, supported by experiments, is conducted aimed at deriving appropriate relations for the in-plane/out-of-plane capacity interaction in unreinforced brick walls. Through a comprehensive parametric study, the main affecting parameters are recognized and their influences on the capacity interaction are established. The parametric study indicates that the aspect ratio of the wall and the elastic and inelastic material properties in tension have the most influence on the level of the in-plane and out-of-plane capacity interaction in masonry walls. Based on the results of these investigations, representing empirical analytical relations for evaluating the interaction are derived and their accuracy is verified.
\end{abstract}

Keywords: masonry, brick wall, in-plane shear, out-of-plane bending, strength capacity interaction, seismic response 


\section{INTRODUCTION}

During earthquake ground motion, a brick wall is simultaneously subjected to inplane and out-of-plane loads. The former result from the storey shear force and the latter are either due to the out-of-plane inertia force of the wall itself or the out-of-plane action of the floor on the wall. Considerable experimental, analytical and numerical studies have been reporte $2 \mathrm{~d}$ on the behaviour of brick walls under earthquake loading, but most of it concentrates on the response and capacity of the wall under in-plane shear loading. Notable experimental works carried out on the in-plane response of unconfined brick walls include those reported by Sinha and Hendry [1], Abrams [2] and Tomazevic [3]. The in-plane shear capacity of confined brick walls was also investigated experimentally by Tomazevic and Klemenk [4], Pourazin and Eshghi [5] and Riahi et al [6]. Factors affecting the in-plane brick wall capacity, including the brick mortar bond strength and the effects of mortar joints have also been investigated experimentally by El-Sakhawy et al [7], Abdou et al [8] and Maheri et al [9-11].

A number of experimental work is also reported for the strength and response of brick walls under out-of-plane loads, highlighting the orthotropic nature of brick wall response [11], the influence of pre-compression and slenderness ratio $[12,13]$ and the effects of brickmortar bond [11] under such loading. A comprehensive review of the above works is given by the authors in [14].

In addition to the above experimental works, numerous numerical investigations have also been carried out in recent years to further study the response of brick walls to in-plane and out-of-plane loading. One of the early works on numerical modelling of unreinforced masonry walls was carried out by Page [15]. He developed a simple micro model for unreinforced masonry subjected to in-plane loads. He applied combined Mohr-Coulomb and 
Maximum Tensile Strength failure surfaces to model the failure in the mortar joints. In Page's model, the masonry unit behaviour was considered elastic brittle and the nonlinear response of the wall was assumed to be solely due to mortar joints behaviour. Later, Ali and Page [16] presented a finite element micro model to simulate the behaviour of masonry under large compressive point loads. They used the Von Mises criterion with tension cut off failure criteria in their model. Their approach could also model smeared cracks in the walls. Lotfi and Shing [17] also developed a simple micro modelling approach for in-plane shear analysis of masonry walls. They used Mohr-Coulomb material model together with maximum tensile strength failure surfaces to model bond slip and tension failure in joints. The smeared crack model was also utilised to obtain cracking in masonry units. Another micro model capable of modelling different in-plane failures in unreinforced brick walls was developed by Lourenço and Rots [18]. They presented two interface models; one was to model failure in bricks and the other was to simulate failure in mortar joints. They applied Mohr-Coulomb failure criteria with combination of a tension cut off and cap model [18]. Chaimoon et al [19] also adopted a micro modelling approach similar to that developed by Lourenço and Rots. Mojsilovic and Marti [20] developed a numerical sandwich model for masonry walls. They also used MohrCoulomb failure criteria for modelling the bed joints and neglected shear capacity of the mortar head joints. They assumed that the mortar head joints work only in compression. Suttcliffe et al [21] applied the lower bound limit analysis method to analyse masonry shear walls subjected to in-plane loads. They used a simple micro model in their analyses and considered plane strain behaviour for the walls. They also adopted the Mohr-Coulomb failure criteria with a cap.

Parallel to the development of micro modelling approaches, several macro models have also been developed by different researchers. Lourenço et al [22] presented an orthotropic composite failure surface for macro modelling of unreinforced masonry subjected 
to in-plane loads. The failure surface is composed of a Rankine type failure surface in tension and a Hill type failure surface in compression. The model was applied to the out of plane behaviour of masonry walls investigated in another work conducted by Lourenço [23]. Other failure surfaces are also developed for masonry such as the failure surface presented by Andreaus [24]. Many investigations have also been carried out on developing homogenization techniques in masonry walls, bridging the gap between micro and macro models, including those reported by Lourenço et al [25], Mistler et al [26] and Milani [27].

Numerical and analytical approaches for the analysis of masonry walls under out-ofplane loads have also been addressed. Sinha et al [28] presented a failure criteria and an analytical method for masonry panels subjected to two-way bending. The limit analysis approach together with homogenization techniques are often applied for the analysis of masonry walls subjected to out-of-plane loads, e.g. Cecchi et al [29], Milani [30] and Casolo and Milani [31].

Despite the large volume of experimental, numerical and analytical works carried out on the response of masonry walls to separate effects of in-plane and out-of-plane loads, very little is reported on the response of masonry subjected to combined effects of in-plane and out-of-plane actions. The few reported works combining the in-plane and out-of-plane actions on the wall seem to be related to the masonry infills. Shapiro et al [32] carried out a series of tests to investigate the effects of in-plane cracks on the out-of-plane strength of brick infills in concrete frames. Their test results showed that the in-plane cracks may reduce the out-ofplane strength of infills by up to $100 \%$. A similar experimental study was carried out by Falangan et al [33] on brick infills in steel frames. Also, Hashemi and Mosalam [34] conducted an in-plane shaking table test on a reinforced concrete infilled frame, subsequently used to calibrate a numerical model that was developed to include out-of-plane loading. 
Recently, an experimental investigation aimed at determining the in-plane and out-ofplane capacity interaction of masonry walls was presented [14]. In that work, the results of a series of tests on small brick walls undergoing different levels of simultaneous in-plane and out-of-plane actions were presented. The test results indicated noticeable interaction between the in-plane shear and out-of-plane bending strengths of brick walls. Test results were also used to validate representing numerical models of wall panels. The combined in-plane/out-ofplane capacity interaction in full-scale walls having three different aspect ratios was then numerically investigated; results of which showed that the wall aspect ratio highly influences the level of interaction [14].

In the following, representing numerical models are developed and their accuracy is verified against experimental data. A comprehensive parametric study is undertaken to recognize the main affecting parameters and to establish their influence on the capacity interaction curves. Based on the results of these investigations, representing relations for evaluating the in-plane and out-of-plane interaction in brick walls are derived and their validity is verified.

\section{VALIDATION OF THE NUMERICAL APPROACH}

In this section, the numerical model used for the parametric study is presented and its accuracy in predicting the in-plane/out-of-plane interaction is verified against existing experimental data. Because of the complex nature of in-plane and out-of-plane actions on the

wall, a suitable continuum macro model based on anisotropic plasticity is adopted [35] for the three dimensional analysis of brick walls. This material model is implemented in software Diana V9.4 [36] via a user supplied subroutine.

\subsection{Anisotropic Continuum Model}


The composite yield criterion used in this model, is based on the plane stress anisotropic yield criterion of Lourenço [22], in the typical five stress component space, with two normal stresses $\sigma_{\mathrm{x}}$ and $\sigma_{\mathrm{y}}$ and three shear stresses $\tau_{\mathrm{xy}}, \tau_{\mathrm{yz}}$ and $\tau_{\mathrm{xz}}$. The composite yield criterion shown in Fig. 1, includes a Hill type criterion for compression and a Rankine type criterion for tension. For an orthotropic material with different tensile strengths along the $x$ and $y$ directions the Rankine type yield surface is given by:

$$
f_{1}=\frac{\left(\sigma_{x}-\overline{\sigma_{t x}}\left(\kappa_{t}\right)\right)+\left(\sigma_{y}-\overline{\sigma_{t y}}\left(\kappa_{t}\right)\right)}{2}+\sqrt{\frac{\left(\sigma_{x}-\overline{\sigma_{t x}}\left(\kappa_{t}\right)\right)-\left(\sigma_{y}-\overline{\sigma_{t y}}\left(\kappa_{t}\right)\right)}{2}+\alpha \tau_{x y}^{2}}
$$

where, $\overline{\sigma_{t x}}$ and $\overline{\sigma_{t y}}$ are the yield values along $\mathrm{x}$ (parallel to bed joints) and y (normal to bed joints) directions. The scalar $\left(k_{t}\right)$ denotes the amount of softening simultaneously in the two material axes. The parameter $\alpha$ which controls the shear stress contribution to failure is given by:

$$
\alpha=\frac{f_{t x} f_{t y}}{\tau_{u, t}^{2}}
$$

where, $f_{t x}, f_{t y}$ and $\tau_{u, t}$ are respectively, the uniaxial tensile strengths in the $x$ and $y$ directions and the pure shear strength.

The adopted compressive yield criterion is a rotated centred ellipsoid in the full stress space (Hill type criterion). The expression for such a quadric can be written as:

$$
f_{2}=\frac{\overline{\sigma_{c y}}\left(\kappa_{c}\right)}{\overline{\sigma_{c x}}\left(\kappa_{c}\right)} \sigma_{x}^{2}+\beta \sigma_{x} \sigma_{y}+\frac{\overline{\sigma_{c x}}\left(\kappa_{c}\right)}{\overline{\sigma_{c y}}\left(\kappa_{c}\right)} \sigma_{y}^{2}+\gamma\left(\tau_{x y}^{2}+\tau_{y z}^{2}+\tau_{x z}^{2}\right)-\overline{\sigma_{c x}}\left(\kappa_{c}\right) \overline{\sigma_{c y}}\left(\kappa_{c}\right)=0
$$

where, $\overline{\sigma_{c x}}\left(\kappa_{c}\right)$ and $\overline{\sigma_{c y}}\left(\kappa_{c}\right)$ are the yield values along the material $x$ and $y$ axes, respectively. 
The $\beta$ and $\gamma$ values are additional material parameters that determine the shape of the yield criterion. They control, respectively, the coupling between the normal stress values and the shear stress contribution to failure. Based on different experimental test results, a value of -1.0 is recommended for $\beta$, ref c. The parameter $\gamma$ may be obtained from the following equation:

$$
\gamma=\frac{f_{c x} f_{c y}}{\tau_{u, c}^{2}}
$$

In the above equation, $f_{c x}, f_{c y}$ and $\tau_{u, c}$ are respectively, the uniaxial compressive strengths in the $x$ and $y$ directions and the pure shear strength. Based on different experimental test results, a value of 3.0 is recommended for $\gamma$, ref c.

In total, twenty one parameters (nine elastic and twelve inelastic) are needed to compose the above anisotropic material model. The elastic parameters include: the Young's moduli, $E$, the Poisson's ratios, $v$ and the shear moduli, $G$, of the anisotropic material. The inelastic parameters for tension are the tensile strengths along $x$ and $y$ directions $\left(f_{t x}\right.$ and $\left.f_{t y}\right)$, the fracture energies in tension along $x$ and $y$ directions $\left(G_{f x}\right.$ and $\left.G_{f y}\right)$ and the parameter $\alpha$. The inelastic parameters in compression are the compressive strengths along $x$ and $y$ directions $\left(f_{c x}\right.$ and $f_{c y}$ ), the fracture energies in compression along $x$ and $y$ directions $\left(G_{f c x}\right.$ and $\left.G_{f c y}\right)$, the parameters $\beta$ and $\gamma$, and the parameter $k_{c}$ that represents the equivalent plastic strain at peak compressive strength.

\subsection{Verification of Numerical Model}

To validate the numerical models used for the parametric study of the in-plane and out-of-plane capacity interaction, representing models of small brick walls tested previously 
for interaction investigations are analysed and the results are compared with those gathered from the experiments.

Details of the experiments carried out by the present authors can be found in [14]. Tests were conducted on a number of single layer brick wallets, $60 \mathrm{~cm}$ by $60 \mathrm{~cm}$ and $10 \mathrm{~cm}$ thick, to evaluate the in-plane and out-of-plane capacity interaction and to determine the interaction curve. The experimental program on the wall panels was conducted in three phases. First, the ultimate pure in-plane shear capacity of the panels was determined. The inplane load was applied vertically on the diagonal of the brick panels. In the second phase, the capacity of the panels under out-of-plane bending alone was investigated. For this purpose, three out-of-plane loading conditions were considered: (i) two-way bending, (ii) bending parallel to the bed joints and (iii) bending perpendicular to the bed joints. The objective of the two latter tests was to obtain the orthotropic tensile strengths of brickwork in perpendicular directions. The third phase of the experiments consisted of a series of tests on panels with different combinations of in-plane and out-of-plane loads. In each test, the wall panel was first subjected to a certain value of out-of-plane load. Then, while the out-of-plane load was kept constant, the in-plane diagonal compressive load was monotonically increased until failure. In total, five load combinations were tested, corresponding to out-of-plane loads of $33 \%, 50 \%, 67 \%, 83 \%$ and $90 \%$ of the ultimate flexural strength of the panels [14]. Results of the third phase of experiments, in the form of normalised in-plane and out-of-plane capacity interaction curve are presented in Fig. 2. The test results show that the interaction curve for a masonry panel follows an approximately circular curve.

For numerical modelling of the tested brick panels, Diana software's layered shell element (CQ40L) with seven Simpson integration points along the height is used. The material parameters used in the models are listed in Table 1 . The material parameters used in the models are derived from the materials tests conducted previously, from literature (see [36] for 
details on recommended inelastic properties) and from the pure shear and bending tests. The compressive strengths and the modulus of elasticity of masonry in two orthogonal directions (along and normal to bed joints), are obtained from the compressive tests on masonry prisms. The fracture energy values used in this study (listed in Table 1) are obtained from the ductility factor, equal to the ratio between the fracture energy and the ultimate strength, for the horizontal tensile strength and the compressive strength. For the vertical tensile strength, the fracture energy values are obtained from the few tests available in the literature [37]. For the compressive strength, a ductility factor of $1.25 \mathrm{~mm}$ is used [35]. The tensile strength parallel to the bed joints is controlled by the failure of the brick and a ductility factor of 0.05 $\mathrm{mm}$ was used [35]. Also, it is noted that the flexural tensile strength cannot be directly compared to the uniaxial tensile strength, because the flexural tensile strength depends on the height of the specimen and on the fracture energy. As a result, masonry direct tensile strength in each direction is considered to be $50 \%$ of the indirect tensile strength in that direction listed in Table 2. Similar to the tests discussed above, numerical model of the brick panel was subjected to three different types of loading. These included pure in-plane diagonal compressive force, pure out-of-plane point load and simultaneous in-plane and out-of-plane loading. The normalised numerical interaction curve for the brick panel undergoing different levels of simultaneous in-plane and out-of-plane loading is compared with the interaction curve obtained from the experiments in Fig. 2. Considering the complexities in simultaneous in-plane and out-of-plane actions, and the small size of the brick panels investigated, the numerical model predicted well the capacity interaction in the brick panels. The differences between experimental and numerical results are below $10 \%$ and the numerical prediction of the interaction curve is conservative.

\section{PARAMETRIC INVESTIGATION OF INTERACTION}


Nonlinear analyses of the brick masonry walls under pure in-plane and out-of-plane loads were carried out and their respective capacities were determined. The out-of-plane load was applied in a uniformly distributed way on the entire area of the wall, to better represent the seismic action. The in-plane load was applied horizontally at the top of the wall. The top and bottom edges of the walls were restrained with compression only supports in vertical direction under the in-plane loading of the wall. This allowed the wall to separate from its support if the edge was in tension. The bottom edge of the wall was also restrained from moving in the horizontal direction against the horizontal in-plane load. The walls were considered simply supported against out-of-plane load on four sides. Also, since shell elements are used for modeling of the walls and the wall edges can rotate freely, the in-plane boundary conditions do not affect the out of plane response of the wall with arching action. After the pure in-plane and out-of-plane capacities of the walls were established, the walls were subjected to simultaneous loading and their interactive capacities were determined. Loading of the walls was carried out in the same manner as that carried out for the brick panels; i.e. a specific amount of constant out-of-plane load was first applied to the wall, followed by the incremental application of the in-plane load until the wall failed.

Many parameters can affect the in-plane and out-of-plane capacity interaction in full scale brick walls. These parameters can be grouped into two categories: geometric parameters and material properties. The effect of wall's aspect ratio has been studied numerically in [14] and the capacity interaction was found to be strongly influenced by this parameter. In particular, three different walls with dimensions of $3 \mathrm{~m} \times 6 \mathrm{~m}, 3 \mathrm{~m} \times 3 \mathrm{~m}$ and $3 \mathrm{~m} \times 1.5 \mathrm{~m}$, respectively, corresponding to aspect (height/length) ratios of $0.5,1$ and 2 , were investigated in the referenced work. Similar to the brick panels, the full-scale walls were one brick thick.

To investigate the influence of additional geometric and material properties of a brick wall on its in-plane and out-of-plane capacity interaction, a series of parametric numerical 
studies are carried out as discussed in this section. The effect of each prospective parameter was evaluated separately by keeping other parameters constant; in effect, ignoring any possible interacting influence among different parameters. The constant base values for different parameters were assumed to be the same as the values used in the brick panels investigation discussed in section 2.2 and listed in Table 1. The numerical models used are also similar to those utilised for evaluating the interaction in test panels. Similarly, software DianaV9.4 was used for evaluating the interaction curves. In the following, the effects of different variable parameters on the in-plane and out-of-plane capacity interaction curves are discussed. It should be noted that since the macro modelling approach is chosen for numerical studies, the block and mortar size effects on the interaction curve could not be investigated. Typical shear stress distributions for one of the walls $(H / L=1.0)$ subjected to simultaneous in-plane and out-of-plane loads are superimposed on the FE model of the wall in Fig. 3.

The normalized interaction curves obtained numerically here and in [14] for the walls having three different aspect ratios $(\mathrm{H} / \mathrm{L}=0.5,1.0$ and 2.0) are plotted in Fig. 4. Here, $\mathrm{H}$ is the height of the wall and L is the length of the wall. Nonlinear regression on the numerically calculated interaction curves indicates that a general equation with the form of equation 5 can be fitted on the curves. The powers a and $b$ can be evaluated by nonlinear regression for each wall as will be discussed later.

$$
\left(\frac{P_{i l}}{P_{i c}}\right)=\left(1-\left(\frac{P_{o l}}{P_{o c}}\right)^{a}\right)^{b}
$$

In equation (5), $P_{i l}$ is the in-plane load, $P_{o l}$ is the out of plane load and $P_{i c}$ and $P_{o c}$ are the pure in-plane and out-of-plane capacities of the wall, respectively. Also, $a$ and $b$ are powers that depend on the aspect ratio of the wall and its material properties. The values of $a$ and $b$ for the three aspect ratios investigated using the base material properties (Table 1) are listed 
in Table 2. Equations relating the powers $a$ and $b$ to the wall aspect ratio may be determined by a curve fitting process on the data tabulated in Table 2 as follows:

$a=1.47(H / L)^{2}-3.2(H / L)+2.53$

$b=0.17(H / L)^{2}-0.05(H / L)+0.23$

To ascertain the validity of equations 5 and 6 , the interaction curves evaluated using these equations for the walls with three different aspect ratios using the base material properties are also plotted in Fig. 4 as dashed lines. Close agreements can be seen between the actual numerical interaction curves and the curve obtained using the presented approximate analytical formulation.

As it was noted above, powers a and $\mathrm{b}$ presented in equation 6 are related to the walls with three different aspect ratios, but having base material properties. In the following, a parametric investigation is carried out to determine the effects of other affecting parameters, besides aspect ratio, including size and material properties.

\subsection{Size Effect}

To investigate the effects of the wall size on the capacity interaction, normalised interaction curves for square walls $(\mathrm{H} / \mathrm{L}=1.0)$ having sides equal to $2 \mathrm{~m}, 3 \mathrm{~m}, 3.6 \mathrm{~m}, 4 \mathrm{~m}$ and $6 \mathrm{~m}$ are evaluated as presented in Fig. 5. It should be noted that only the planar dimensons of the wall are considered variable and the wall thickness is kept constant as one brick thick $(10 \mathrm{~cm})$; therefore, the effects of wall slenderness ratio is not considered in this study, and they must be considered by an additional slenderness correction factor. This figure indicates that the level of interaction in the wall decreases with increasing wall size, meaning that for the same out-of-plane load / out-of-plane capacity, an increasing size provides a higher in-plane normalized capacity. Since in building construction the storey height is generally around 3.0 $\mathrm{m}$, this size is used in the analytical investigations as the base size. Also, the interaction 
curves of the square wall with side equal to $3.0 \mathrm{~m}$ (base size) can be possibly considered as conservatively representing walls with practical dimensions, as it is close to the minimum interaction curve obtained (see Fig. 5).

\subsection{Material properties effects}

In this section, the effect of each of the elastic and non-elastic material properties on the level of interaction is investigated. Interaction curves are evaluated with each parameter attaining different values (only one parameter changed at each time) and for all different aspect ratios. The boundary conditions, loading types and the analysis procedure are similar to those considered in the geometrical parametric studies described in the previous section. The values assigned to the material properties in the parametric study are presented in Table 3. The values are selected such that a realistic and practical value range for that parameter is covered. In Table 3, the values highlighted as bold numbers are the base material properties considered in the previous sections.

\subsubsection{The effects of elastic material properties}

As it was mentioned earlier, the elastic parameters considered for the sensitivity study include: modulus of elasticity of masonry along x (along the bed joints) and y (normal to bed joints) directions ( $E_{x}$ and $\left.E_{y}\right)$ and the shear modulus of masonry $(G)$. As shown in Table 3, four different values, ranging from $8000 \mathrm{MPa}$ to $24000 \mathrm{MPa}$ are considered for $E_{x}$. The normalised in-plane/out-of-plane interaction curves for each of the three walls having different values of $E_{x}$ are plotted and compared in Fig. 6. This figure shows that by increasing the value of the modulus of elasticity in $\mathrm{x}$ direction, the in-plane/out-of-plane capacity 
interaction increases. However, the rate of increase in walls having different aspect ratios varies. In walls with $\mathrm{H} / \mathrm{L}=1.0$ and $\mathrm{H} / \mathrm{L}=2.0$, the curves approach a unique limiting curve with increasing modulus of elasticity, whereas, in the wall with $\mathrm{H} / \mathrm{L}=0.5$ the increase in interaction due to $E_{x}$ is uniform.

Normalised interaction curves for the three walls under consideration having four different values of modulus of elasticity in y direction (normal to bed joints), $E_{y}$, ranging from $4000 \mathrm{MPa}$ to $12000 \mathrm{MPa}$ are plotted in Fig. 7. Results show that, similar to the case of $E_{x}$, in all three walls, the interaction between the in-plane and out-of-plane capacity, increases by increasing $E_{y}$. However, it appears that the effect of $E_{y}$ on the capacity interaction in walls with various aspect ratios is less profound than that of $E_{x}$. This seems realistic because: (a) the horizontal tensile strength is larger than the vertical tensile strength; (b) is the wall is slender the vertical tensile strength has a more pronounced effect in the response.

The influence of shear modulus, $G$, on the interaction curves was also investigated by considering four different values listed in Table 3. The resulting normalised interaction curves for walls with different aspect ratios are compared in Fig. 8. Results indicate that $G$ influences the interaction curves in a similar way for walls with $\mathrm{H} / \mathrm{L}=1.0$ and $\mathrm{H} / \mathrm{L}=2.0$; in both cases the level of interaction decreases with increasing shear modulus. For the wall with $\mathrm{H} / \mathrm{L}=0.5$, the effect is somewhat different. In this wall, for out-of-plane loads up to $40 \%$ of the out-of-plane capacity, $G$ appears not to affect the interaction curve; however, for higher loads, interaction increases with increasing $G$. The difference in the response of the squat wall $(\mathrm{H} / \mathrm{L}=0.5)$ to changing $G$, compared to taller walls may be attributed to the prominence of shear in this wall.

Although in limit analysis approaches the elastic material properties do not affect the ultimate capacity of the wall, in nonlinear finite element numerical analyses, elastic properties affect the inelastic distribution of stresses (as the stress-strain curves change). 
Therefore, elastic material properties affect slightly the capacity of structural elements, see e.g. refl or structures, see e.g. ref2.

\subsubsection{The effects of inelastic material parameters in tension}

Inelastic material properties in tension are tensile strengths of masonry in $\mathrm{x}$ and $\mathrm{y}$ directions $\left(f_{t x}\right.$ and $\left.f_{t y}\right)$, tensile fracture energies in tension along $\mathrm{x}$ and $\mathrm{y}$ directions $\left(G_{f x}\right.$ and $\left.G_{f y}\right)$ and parameter $\alpha$. The interaction curves for walls with three aspect ratios are evaluated with each of the mentioned material properties in turn assuming different values. One exception is that, at first, the fracture energy was assumed to be linearly dependent on the tensile strength and changed simultaneously with tensile strength.

To investigate the effects of masonry tensile strength in $\mathrm{x}$ direction $\left(f_{t x}\right)$, interaction curves for the three walls having four different values of this parameter (listed in Table 3) are evaluated as presented in Fig. 9. Parameter $f_{t x}$ has a profound effect on the interaction curves of all three masonry walls, drastically decreasing the level of interaction as its value increases. Also, in the taller wall having $\mathrm{H} / \mathrm{L}=2.0$, the interaction curves approach a constant limiting curve as $f_{t x}$ decreases. In the other two walls, the change in the interaction curve due to changing $f_{t x}$ follows a more uniform trend.

Similarly, the effects of masonry tensile strength in y direction $\left(f_{t y}\right)$ on the interaction curves were determined by evaluating the interactions for four different values of $f_{t y}$. Results for the square wall are presented in Fig. 10(a), where similar interaction curves of the three masonry walls are found for parameter $f_{t y}$. The interaction is not that sensitive to the parameter $f_{t y}$ in the wall with $\mathrm{H} / \mathrm{L}=0.5$, while in the wall with $\mathrm{H} / \mathrm{L}=2.0$, the effects are considerable.

The fracture energy and strength are interdependent parameters; however, they may affect the interaction curves in different forms and to different degrees. To determine the 
influence of the tensile fracture energies in x and y directions $\left(G_{f x}\right.$ and $\left.G_{f y}\right)$ on the masonry inplane and out-of-plane capacity interaction, all other parameters were kept constant and in turn only $G_{f x}$ and $G_{f y}$ were assumed variable. Normalised interaction curves were evaluated using four different values of $G_{f x}$ and four different values of $G_{f y}$. Results for the square wall $(\mathrm{H} / \mathrm{L}=1.0)$ are plotted in Fig. 10(b) for $G_{f x}$ and Fig. 10(c) for $G_{f y}$. Fig. 10(b) shows that the effects of parameter $G_{f x}$ on interaction curves of masonry walls are somewhat similar to the effects of parameters $f_{t x}$ and $G_{f x}$ when considered together; indicating that most of the effects seen when carrying out sensitivity study on $f_{t x}$ and $G_{f x}$ were indeed due to changes in the tensile fracture energy, $G_{f x}$. In walls with $\mathrm{H} / \mathrm{L}=1.0$ and $\mathrm{H} / \mathrm{L}=2.0$, the interaction decreases as fracture energy increases. On the other hand, in wall with $\mathrm{H} / \mathrm{L}=0.5$ the effects of fracture energy on interaction curves are negligible. This is particularly true for low values of out-ofplane loads.

Regarding the effects of tensile fracture energy in y direction, $\left(G_{f y}\right)$ on the interaction curve, Fig. 10(c) confirms the relevance of the tensile fracture energy parameter. Also, in walls with $\mathrm{H} / \mathrm{L}=1.0$ and $\mathrm{H} / \mathrm{L}=2.0$, the interaction trend approaches a limiting curve as the parameter $G_{f y}$ increases.

The final inelastic parameter in tension considered here is the parameter $\alpha$. Three different values of $\alpha$ were considered for determining the sensitivity of the results to this parameter. The interaction curves obtained for the wall with $\mathrm{H} / \mathrm{L}=1.0$ having different values of $\alpha$ are plotted in Fig. 10(d). Results indicate moderate effects of parameter $\alpha$ on the form of the in-plane, out-of-plane interaction curves of masonry walls with different aspect ratios. In all cases, the interaction increases as $\alpha$ increase. In some cases, for small values of $\alpha$, the out of plane load does not affect the capacity interaction.

\subsubsection{The effects of inelastic material parameters in compression}


Inelastic material properties in compression considered in these sensitivity investigations include; compressive strengths of masonry in $\mathrm{x}$ and $\mathrm{y}$ directions $\left(f_{c x}\right.$ and $\left.f_{c y}\right)$, fracture energies in compression along x and y directions ( $G_{f c x}$ and $\left.G_{f c y}\right)$ and parameters $\beta$ and $\gamma$. Again, the fracture energy was assumed to be linearly dependant on the compressive strength.

Normalised interaction curves for three different values of compressive strength of masonry along the bed joints, $f_{c x}$, and for the square wall are presented in Fig. 11(a). The variation of compressive strength and compressive fracture energy along the bed joints has very little influence on the form of the interaction curves. This appears to be true for all three walls, having different aspect ratios. The general trend is that by increasing $f_{c x}$ (and consequently $G_{f c x}$, interaction slightly increases.

To evaluate the individual effect of $G_{f c x}$ on the interaction curve, the compressive strength along the bed joint was kept constant and only $G_{f c x}$ assumed different values. The interaction curves evaluated for the wall with $\mathrm{H} / \mathrm{L}=1.0$ are presented in Fig. 11(b). It can be seen that the effects of this parameter on the interaction curves are very small and could be ignored. The small influence of combined effects of $f_{c x}$ and $G_{c x}$ noted above, are mostly due to the compressive strength of masonry along $\mathrm{x}$ direction and not to the compressive fracture energy.

To investigate the sensitivity of the interaction curves to the combined effects of compressive strength and compression fracture energy normal to the bed joints ( $f_{c y}$ and $\left.G_{f c y}\right)$, four different values were considered for $f_{c y}$ (Table 3 ). The evaluated interaction curves are compared in Fig. 11(c). The parameter $f_{c y}$ affects the interaction curves on the three walls in an almost similar manner. The influence of this parameter on the interaction curves is well marked, indicating that compressive strength normal to bed joints has stronger effect on interaction compared to the compressive strength parallel to bed joints. 
To determine the influence of compressive fracture energy in the y direction on the inplane and out-of-plane capacity interaction in masonry walls, all other affecting parameters were kept constant while four different values of $G_{f c y}$ were tested. Normalised interaction curves evaluated for the square wall are presented in Fig. 11(d). It is evident that the compressive fracture energy normal to bed joints has negligible effects on the interaction curves.

The effects of the remaining two parameters related to the compression regime ( $\gamma$ and $\beta$ ) on the wall interaction curves are also minimal. Interaction curves for the square wall evaluated using different values for $\gamma$ and $\beta$ are shown in Fig. 12. Fig. 12(a) shows that by increasing $\gamma$ a small increase in interaction occurs; the increase in interaction in the taller wall is less marked. Fig.12(b) indicates that parameter $\beta$ has almost no effects on the interaction curve.

A review of the results obtained from the parametric study discussed above shows that different materials properties have different effects on the in-plane and out-of-plane capacity interaction in brick walls. Based on their effects these material parameters can be categorized into three groups: parameters with almost no impact, parameters with low impact and high impact parameters. Material properties with almost no impact include: compressive strength parallel to bed joints, $f_{c x}$, compressive fracture energies parallel to bed joints $\left(G_{f c x}\right)$ and normal to bed joints $\left(G_{f c y}\right)$ and parameter $\beta$. Material properties having low impact are those with minor effects on the interaction curves or only affecting the interaction in walls with certain aspect ratios. Parameters $\alpha, \gamma, f_{c y}, f_{t y}, G_{f c y}, E_{y}$ and $G$ may be placed in this category. The high impact material properties are recognised as the elastic modulus parallel to bed joints $\left(E_{x}\right)$, tensile strength parallel to the bed joints $\left(f_{t x}\right)$ and tensile fracture energy parallel to bed joints $\left(G_{f x}\right)$. In summary, it appears that generally, the elastic parameters and 
the inelastic parameters in tension regime have considerable effects on the capacity interaction, whereas the effects of the inelastic parameters in compression are less profound.

\section{ANALYTICAL INVESTIGATIONS}

In the following, a semi-empirical procedure for determining the in-plane and out-ofplane interaction curve of a masonry wall with arbitrary material properties is proposed. The method is based on the results of the parametric numerical studies presented. In this method, the interaction curves evaluated for the full scale brick walls with three different aspect ratios, and having material properties the same as the test specimens, are considered as 'base interaction curves' (equations 5 and 6). For a wall with arbitrary material and geometric properties the base interaction curves are corrected with modification factors applied to the powers $a$ and $b$ of equation (5) to account for the difference in material properties. These modification factors are determined by using the interaction curves obtained in the previous section.

Considering that simplicity and accuracy are important characteristics of any analytical approach, it would not be prudent to attempt to include the effects of all material properties discussed to modify the base interaction curve. Indeed, the results of the parametric studies reported above indicated that some of the material properties, such as the inelastic parameters in compression, have minor effects on the shape of the interaction curve. On the other hand, some material properties, such as parameters $\alpha, \beta$ and $\gamma$ used in the numerical model, are not clear for most users. Therefore, the material property parameters considered for capacity interaction evaluation are categorized into two groups: primary and secondary. The primary parameters are those that have considerable effects on the in-plane 
and out-of-plane capacity interaction in masonry walls, as defined by the results of the parametric studies. The secondary parameters are those that do not have significant influence on the shape of the normalised interaction curve and they include; wall size, $f_{c x}$ and $f_{c y}$. Parameters $\alpha, \beta$ and $\gamma$ are also included in this category. Therefore, these parameters are assumed to influence the interaction curves only indirectly.

To account for the effects of the secondary parameters, a minimum curve is passed through the interaction curves obtained for these parameters. In other words, the minimum curve is an interaction curve that consists of a series of points with minimum in-plane strength corresponding to each level of the out-of-plane load of all the interaction curves obtained from the parametric studies related to the secondary material properties. The minimum interaction curves for walls with different aspect ratios are presented in Fig. 13. Similar to the equations derived for evaluating the base interaction curves, an equation with the general form of equation 5 may also be considered for the minimum interaction curves. On the other hand, the influence of primary parameters such as $f_{t x}, f_{t y}, E_{x}, E_{y}$ and $G$ is taken into consideration through modification factors. As a result, the following modified interaction curve is now proposed to account for the variable nature of geometric and material properties of the wall.

$$
\left(\frac{P_{i l}}{P_{i c}}\right)_{m}=\left(1-\left(\frac{P_{o l}}{P_{o c}}\right)^{a_{m}}\right)^{b_{m}}
$$

In the above equations, $\left(\frac{P_{i l}}{P_{i c}}\right)_{m}$ is the new modified interaction curve and $a_{m}$ and $b_{m}$ are the modified powers determined as follows:

$$
a_{m}=\left(1+\sum_{i=1}^{n} C_{a i}\right) a_{\min }
$$


$b_{m}=\left(1+\sum_{i=1}^{n} C_{b i}\right) b_{\min }$

where, $a_{\min }$ and $b_{\min }$ are the powers relating to the minimum interaction curve obtained to account for the effects of secondary material properties. These powers for walls with different aspect ratios are presented in Table 4 . The values listed in Table 4 can also be related to the wall aspect ratio $(H / L)$ in the following form:

$a_{\text {min }}=0.87(H / L)^{2}-1.5(H / L)+1.23$
$b_{\text {min }}=0.23(H / L)^{2}-0.15(H / L)+0.27$

Also, in equations (8) and (9) $C_{a i}$ and $C_{b i}$ are the modification factors considered for the effects of different primary material properties, $i$. These modification factors are obtained as the ratios of the powers of the interaction curve of the wall evaluated for the considered material property to the powers of the base interaction curve as follows:

$$
\begin{aligned}
& C_{a i}=\left(a_{i} / a\right)-1 \\
& C_{b i}=\left(b_{i} / b\right)-1
\end{aligned}
$$

In equation (11), $a$ and $b$ were previously defined in equation (6) as the powers for the base materials and $a_{i}$ and $b_{i}$ are the powers in the interaction curves of the walls having variable primary material properties. These powers were calculated for every primary material property and are presented graphically in Figs. 14 to 18 . The non-smooth rate of change of these parameters with the change in the material properties noted in these figures is due to the nonlinear regression used to obtain the powers. To simplify the evaluation of these powers, the following equation is fitted to the data presented in Figs. 14 to 18.

$$
a_{i} \& b_{i}=\frac{a_{1} P_{i}^{x_{1}}+a_{2}(H / L)^{y_{1}}+a_{3}}{b_{1} P_{i}^{x_{2}}+b_{2}(H / L)^{y_{2}}+b_{3}} \quad \begin{aligned}
& a_{i} \geq 0.6 \\
& b_{i} \geq 0.1
\end{aligned}
$$


where, $P_{i}$ is the value of the considered primary material property. Also, coefficients $a_{1}$ to $a_{3}$ and $b_{1}$ to $b_{3}$, and powers $x_{i}$ and $y_{i}$, for different primary material properties, determined by application of nonlinear regression, are given in Table 5. It should be noted that the above equations are derived and verified for the broad range of values considered for different geometrical and material properties in the numerical analyses (Table 3).

The proposed semi-empirical approach presented above can be summarized in the following steps:

1- Using Table 5, determine the coefficients $a_{1}$ to $a_{3}$ and $b_{1}$ to $b_{3}$ and powers $x_{i}$ and $y_{i}$ for every primary material property, $f_{t x}, f_{t y}, E_{x}, E_{y}$ and $G$.

2- Using the considered value for each primary material property, $P_{i}$ and the wall aspect ratio $(H / L)$, determine powers $a_{i}$ and $b_{i}$ by applying equation (12).

3- Use equation (6) to evaluate powers $a$ and $b$, relating to the base primary material properties.

4- Determine the modification factors for the primary material properties, $C_{a i}$ and $C_{b i}$, using equation (11).

5- Determine the powers relating to the minimum curve of the secondary parameters, $a_{\min }$ and $b_{\min }$, by using equation (10).

6- Use equations (8) and (9) and the parameters evaluated in steps (4) and (5) to calculate the modified powers; $a_{m}$ and $b_{m}$.

7- Apply the powers $a_{m}$ and $b_{m}$ to the interaction equation (7) to evaluate the required capacity.

To investigate the reliability of the proposed semi-empirical method, interaction curves, evaluated using this method, were compared with the numerical interaction curves. In most cases the difference between the analytical and numerical results falls within a $10 \%$ 
range and the difference is always smaller than $20 \%$. Also, the results indicate that the interaction curves evaluated using the proposed analytical solution are always on the safe side. To further investigate the applicability of the semi-empirical method to any arbitrary brick wall, the method was also used to evaluate the in-plane/out-of-plane interaction in three different walls having arbitrary geometric and material properties. The properties considered for the walls are listed in Table 6 . The interaction curves obtained for the walls using both the proposed semi-empirical method and the numerical method are compared in Fig. 19. This shows that the proposed method produces conservative results with very good accuracy.

\section{CONCLUSIONS}

A program of numerical investigations aimed at evaluating the effects of different geometric and material properties on the in-plane and out-of-plane capacity interaction in brick walls was reported. Through a comprehensive parametric study, the main affecting parameters are recognized and their influences on the capacity interaction are established. It is found that of the affecting parameters the wall's aspect ratio, the elastic material properties and the inelastic material properties in tension have the most influence on the level of interaction and the shape of the interaction curve. Based on the results of the parametric study, a simple, representing analytical approach was developed for determining the inplane/out-of-plane capacity interaction curves in brick walls. It was shown that the proposed analytical method produces results that are accurate and on the safe side.

\section{References}

[1] Sinha, B. P., Hendry, A. W., Racking tests on storey-height shear wall structures with openings subjected to pre-compression. Designing, engineering and constructing with masonry products, Gulf Publishing Company, Houston, 1969: 192-199. 
[2] Abrams, D. P., Strength and behavior of unreinforced masonry elements, Proceedings of the $10^{\text {th }}$ world conference on earthquake engineering, Madrid, 1992: 3475-3480.

[3] Tomazevic, M., Shear resistance of masonry walls and Eurocode 6: shear versus tensile strength of masonry, Materials and Structures, 2009; 42: 889-907.

[4] Tomasevic, M., Klemenc, I., Seismic behaviour of confined masonry walls, Earthquake Engineering and Structural Dynamics, 1997; 26: 1059-1071.

[5] Pourazin, Kh., Eshghi, S., Experimental and analytical studies for development of capacity curves in a confined masonry wall, Journal of Performance for Constructed Facilities, 2009; 5: 123-134.

[6] Riahi, Z., Elwood, K. J., Alcocer, S. M., Backbone Model for Confined Masonry Walls for Performance-Based Seismic Design, J. Structural Engineering, ASCE, 2009; 135(6): 644654.

[7] El-Sakhawy, N. R., Raof, H. A., Gouhar, A., Shearing behaviour of joints in load bearing masonry wall, J. Materials in Civil Engineering, 2002;14(2): 145-150.

[8] Abdou, L., Saada, R. A., Meftah, F., Mebarki, A., Experimental investigation of the brickmortar interface behavior, Experimental investigation of the mortar joint in masonry structures, Mechanics Research Communications, MRC 969, 2005.

[9] Maheri, M. R., Sherafati M. A., The effects of humidity and other environmental parameters on the shear strength of brick walls; evaluation of field test data, Materials and Structures. 2012, DOI: 10.1617/s11527-011-9809-7.

[10] Maheri, M. R., Motielahi, F., Najafgholipour, M. A., The effects of pre and post construction moisture condition on the in-plane and out-of-plane strengths of brick walls, Materials and Structures, 2011; 44(2): 541-559.

[11] Maheri, M. R., Najafgholipour, M. A., Rajabi, A. R., The influence of mortar head joints on the in-plane and out of plane seismic strength of brick masonry walls, Iranian J. Science and Technology, 2011; 35: 63-79.

[12] Griffith, M. C., Vaculik, J., Lam, N. T. K., Wilson, J., Lumantarna, E., Cyclic testing of unreinforced masonry walls in two-way bending, Earthquake Engineering and Structural Dynamics, 2007; 36: 801-821.

[13] Derakhshan, H., Ingham, J. M., Griffith, M. C., Out-of-plane behavior of one-way spanning unreinforced masonry walls, Journal of Engineering Mechanics, ASCE, 2013; 139(4): 409-417.

[14] Najafgholipour, M.A., Maheri, M.R., Lourenço, P.B., Capacity interaction in brick masonry under simultaneous in-plane shear and out-of-plane bending loads, Construction and Building Materials, 2013; 38: 619-626.

[15] Page, A. W., Finite element model for masonry. Journal of the Structural Division, ASCE, 1978; 104(ST8): 1267-1285.

[16] Ali, S. S., Page, A. W., Finite element model for masonry subjected to concentrated loads. Structural Engineering, ASCE, 1988; 114(8), 1761-1784. 
[17] Lotfi, H. R., Shing, P. B., Interface model applied to fracture of masonry structures. Structural Engineering, ASCE, 1994; 120(1): 63-80.

[18] Lourenço, B. P., Rots, J. G., Multisurface interface model for analysis of masonry structures. Structural Engineering, ASCE, 1997; 123(7): 660-668.

[19] Chaimoon, K., Attard, M. M., Modeling of unreinforced masonry walls under shear and compression. Engineering Structures, 2007; 29(9): 2056-2068.

[20] Mojsilovic, N., Marti, P., Strength of masonry subjected to combined actions. ACI Structural Journal, 1997; 94(6): 633-641.

[21] Sutcliffe, D. J., Yu, H. S., Page A. W., Lower bound limit analysis of unreinforced masonry shear walls. Computers and Structures, 2001; 79(14): 1295-1312.

[22] Lourenço, P. B., Borst, R. D., Rots, J. G., A plane stress softening plasticity model for orthotropic materials. International Journal for Numerical Methods in Engineering, 1997; 40: 4033-4057.

[23] Lourenço, P. B., Anisotropic softening model for masonry plates and shells. Structural Engineering, ASCE, 2000; 126(9): 1008-1016.

[24] Andreaus, A., Failure criteria for masonry panels under in-plane loading. Structural Engineering, ASCE, 1996; 122(1): 37-46.

[25] Lourenço, P. B., Milani, G., Tralli, A., Zucchini, A., Analysis of masonry structures: review of and recent trends of homogenisation techniques, Canadian Journal of Civil Engineering, 2007; 34 (11):1443-1457.

[26] Mistler, M., Anthoine, A., Butenweg, C., In-plane and out of plane homogenization of masonry, Computers and Structures, 2007; 85: 1321-1330.

[27] Milani, G., Simple homogenization model for the non-linear analysis of in-plane loaded masonry walls, Computers and Structures, 2011; 89: 1586-1601.

[28] Sinha, B. P., Ng, C. L., Pedreschi, R. F., Failure criterion and behavior of brickwork in biaxial bending. Materials in Civil Engineering, ASCE, 1997; 9(2): 70-75.

[29] Cecchi, A., Milani, G., Trailli, A., Validation of analytical multiparameter homogenization models for out-of-plane loaded masonry walls by means of the finite element method, Journal of Engineering Mechanics, ASCE, 2005; 131(2): 185-198.

[30] Milani, G., Simple lower bound limit analysis homogenization model for in- and out-ofplane loaded masonry walls, Construction and Building Materials, 2011; 25(12): 4426-4443.

[31] Casolo, S., Milani, G., A simplified homogenization-discrete element model for the nonlinear static analysis of masonry walls out-of-plane loaded. Engineering Structures, 2010; 32(8): 2352-2366.

[32] Shaprio, D., Uzarski, J., Webster, M., Angel, R., Abrams, D., Estimating out of plane strength of cracked masonry infills, University of Illinois at Urbana-Champaign, Civil Engineering Studies, Structural Research Series No. 588, 1994. 
[33] Flanagan, R. D., Bennett, R. M., Bidirectional behaviour of structural clay tile infilled frames. Structural Engineering, ASCE, 1999; 125(3): 236-244.

[34] Hashemi, A., Mosalam, K. M., Seismic Evaluation of Reinforced Concrete Buildings Including Effects of Masonry Infill Walls, Pacific Earthquake Engineering Research Center, University of California, Berkeley, PEER Report 2007/100.

[35] Lourenço, P. B., Anisotropic softening model for masonry plates and shells, Journal of Structural Engineering, ASCE, 2000; 126(9): 1008-1016.

[36] Diana-Finite Element Analysis, User's Manual, Published by TNO Diana BV. Schoemakerstraat 97, 2628 VK Delft, The Netherlands.

[37] Van der Pluijm, R., Out of plane bending of masonry: Behaviour and strength. Ph.D. Dissertation, Eindhoven University of Technology, The Netherlands (1999).

[38] Lourenço, P. B., Recent advances in masonry structures: Micro modelling and homogenisation, in: Multiscale Modeling in Solid Mechanics: Computational Approaches, Eds. U. Galvanetto, M.H. Ferri Aliabadi, Imperial College Press, 2009, 251-294.

[39] Lourenço, P.B., Simulations of size effect in masonry structures, ein: Fracture Mechanics of Concrete Structures, Eds. H. Mihasi and K. Rokugo, Aedificatio, Freiburg, Germany, p. 2001-2010 (1998). 


\section{List of Tables}

Table 1- Material properties of masonry used for numerical studies of brick panels and their coefficient of variation

Table 2- Values of $a$ and $b$ for the base interaction curves of the walls with three aspect ratios Table 3-Values used for material properties in the parametric study (Bold values represent the base values)

Table 4- Values of $a_{\min }$ and $b_{\min }$ for the minimum interaction curves of the walls with different aspect ratios

Table 5- Coefficients of equation (12) for calculation of powers $a_{i}$ and $b_{i}$

Table 6- Material and geometrical properties of the three arbitrary walls

\section{$\underline{\text { List of Figures }}$}

Fig. 1. The plane stress anisotropic yield criterion [22]

Fig. 2. Normalised in-plane, out-of-plane capacity interaction curves for the brick panels [14] Fig. 3-Shear stress distribution in the brickwork of the square wall at the tension plane, corresponding to an out-of-plane load/capacity ratio of 0.6 at (a) $50 \%$ of the ultimate capacity and (b) at failure.

Fig. 4. Normalised numerical interaction curves for full scale walls with three different aspect ratios

Fig. 5. Normalised calculated interaction curves for square walls of different sizes

Fig. 6- The effects of modulus of elasticity along bed joints $\left(E_{x}\right)$ on the capacity interaction curves of walls with (a) $\mathrm{H} / \mathrm{L}=0.5$, (b) $\mathrm{H} / \mathrm{L}=1.0$ and (c) $\mathrm{H} / \mathrm{L}=2.0$

Fig. 7- The effects of modulus of elasticity normal to bed joints $\left(E_{y}\right)$ on the capacity interaction curves of walls with (a) $\mathrm{H} / \mathrm{L}=0.5$, (b) $\mathrm{H} / \mathrm{L}=1.0$ and (c) $\mathrm{H} / \mathrm{L}=2.0$

Fig. 8- The effects of shear modulus $(G)$ on the capacity interaction curves of walls with (a) $\mathrm{H} / \mathrm{L}=0.5$, (b) $\mathrm{H} / \mathrm{L}=1.0$ and (c) $\mathrm{H} / \mathrm{L}=2.0$

Fig. 9- The effects of tensile strength along bedjoints $\left(f_{t x}\right)$ on the capacity interaction curves of walls with (a) $\mathrm{H} / \mathrm{L}=0.5$, (b) $\mathrm{H} / \mathrm{L}=1.0$ and (c) $\mathrm{H} / \mathrm{L}=2.0$

Fig. 10- Interaction curves for the square wall $(\mathrm{H} / \mathrm{L}=1.0)$, for different values of (a) $f_{t y}$, (b) $G_{t x},(\mathrm{c}) G_{t y}$ and (d) $\alpha$

Fig. 11- Interaction curves for different values of (a) $f_{c x}$, (b) $f_{c y}$, (c) $G_{f c x}$ and (d) $G_{f c y}$

Fig. 12- Interaction curves for different values of (a) $\beta$ and (b) $\gamma$.

Fig. 13- The minimum of the numerical and analytical interaction curves obtained with secondary material properties

Fig. 14- Powers $a_{i}$ and $b_{i}$ for different values of modulus of elasticity along bedjoints 
Fig. 15- Powers $a_{i}$ and $b_{i}$ for different values of tensile strength along bedjoints

Fig. 16- Powers $a_{i}$ and $b_{i}$ for different values of modulus of elasticity normal to bedjoints

Fig. 17- Powers $a_{i}$ and $b_{i}$ for different values of tensile strength normal to bedjoints

Fig. 18- Powers $a_{i}$ and $b_{i}$ for different values of shear modulus

Fig. 19- Comparison of interaction curves obtained with numerical and semi-empirical methods

Table 1- Material properties of masonry used for numerical studies of brick panels and their coefficient of variation

\begin{tabular}{|c|c|c|c|c|}
\hline Property & Symbol & $\begin{array}{c}\text { Value } \\
(\boldsymbol{C . O . V})\end{array}$ & $\begin{array}{c}\text { Standard } \\
\text { No. of } \\
\text { Specimens }\end{array}$ \\
\hline Compressive strength normal to bedjoints (MPa) & $f_{c y}$ & $\begin{array}{c}8.0 \\
(6.3 \%)\end{array}$ & $\begin{array}{c}\text { ASTM C1314- } \\
11 \mathrm{a}\end{array}$ & 5 \\
\hline Compressive strength parallel to bedjoints (MPa) & $f_{c x}$ & $\begin{array}{c}4.0 \\
(9.5 \%)\end{array}$ & - & 5 \\
\hline Flexural tensile strength normal to bedjoints (MPa) & $f_{r y}$ & $\begin{array}{c}0.5 \\
(7.5 \%)\end{array}$ & ASTM E518-10 & 5 \\
\hline Flexural tensile strength parallel to bedjoints (MPa) & $f_{r x}$ & $\begin{array}{c}3.0 \\
(5.6 \%)\end{array}$ & - & 3 \\
\hline Young's modulus normal to bedjoints (MPa) & $E_{x}$ & $\begin{array}{c}8000 \\
(8.1 \%)\end{array}$ & $\begin{array}{c}\text { ASTM C1314- } \\
11 \mathrm{a}\end{array}$ & 5 \\
\hline Young's modulus parallel to bedjoints (MPa) & $E_{y}$ & $\begin{array}{c}12000 \\
(9.4 \%)\end{array}$ & - & 5 \\
\hline
\end{tabular}

Elastic parameters

\begin{tabular}{|c|c|c|c|c|c|c|c|c|}
\hline \multicolumn{4}{|c|}{ Young's modulus (MPa) } & \multicolumn{3}{c|}{ Poisson's ratio } & \multicolumn{3}{c|}{ Shear modulus (MPa) } \\
\hline $\mathrm{E}_{\mathrm{x}}$ & $\mathrm{E}_{\mathrm{y}}$ & $\mathrm{E}_{\mathrm{z}}$ & $v_{x y}$ & $v_{x z}$ & $v_{y z}$ & $\mathrm{G}_{\mathrm{xy}}$ & $\mathrm{G}_{\mathrm{xz}}$ & $\mathrm{G}_{\mathrm{yz}}$ \\
\hline 12000 & 8000 & 12000 & 0.2 & 0.2 & 0.2 & 3200 & 3200 & 3200 \\
\hline
\end{tabular}

Inelastic parameters in tension regime

\begin{tabular}{|c|c|c|c|c|}
\hline$f_{t x}(\mathrm{MPa})$ & $f_{t y}(\mathrm{MPa})$ & $G_{f x}$ & $G_{f y}$ & $\alpha$ \\
\hline 1.5 & 0.25 & 0.08 & 0.007 & 1.35 \\
\hline
\end{tabular}

Inelastic parameters in compression regime

\begin{tabular}{|c|c|c|c|c|c|c|}
\hline$f_{c x}(\mathrm{MPa})$ & $f_{c y}(\mathrm{MPa})$ & $G_{f c x}$ & $G_{f c y}$ & $\beta$ & $\gamma$ & $k_{c}$ \\
\hline 4.0 & 8.0 & 5.0 & 10.0 & -1.0 & 10.0 & 0.0005 \\
\hline
\end{tabular}

Table 2- Values of $\mathrm{a}$ and $\mathrm{b}$ for the base interaction curves of the walls with three aspect ratios

\begin{tabular}{|c|c|c|}
\hline $\mathbf{H} / \mathbf{L}$ & $\mathbf{a}$ & $\mathbf{b}$ \\
\hline $\mathbf{0 . 5}$ & 1.3 & 0.25 \\
\hline $\mathbf{1 . 0}$ & 0.8 & 0.35 \\
\hline
\end{tabular}




\begin{tabular}{|l|l|l|}
\hline $\mathbf{2 . 0}$ & 2 & 0.8 \\
\hline
\end{tabular}

\begin{tabular}{|c|c|c|c|c|c|c|}
\hline & Parameter & $\mathbf{1}$ & $\mathbf{2}$ & $\mathbf{3}$ & $\mathbf{4}$ & $\mathbf{5}$ \\
\hline 1 & $\begin{array}{c}\text { Modulus of elasticity along } \\
\text { bedjoints }\left(\mathbf{E}_{\mathbf{x}}\right)(\mathbf{M P a})\end{array}$ & 8000 & $\mathbf{1 2 0 0 0}$ & 16000 & 24000 & - \\
\hline
\end{tabular}

Table 3- Values used for material properties in the parametric study (Bold values represent the base values) 


\begin{tabular}{|c|c|c|c|c|c|c|}
\hline 2 & $\begin{array}{c}\text { Modulus of elasticity normal to } \\
\text { bedjoints }\left(E_{y}\right)(\mathrm{MPa})\end{array}$ & 4000 & 6000 & 8000 & 12000 & - \\
\hline 3 & Shear modulus (G) (MPa) & 1600 & 2400 & 3200 & 4800 & - \\
\hline 4 & $\begin{array}{l}\text { Tensile strength along bedjoints } \\
\left(\mathrm{F}_{\mathrm{tx}}\right)(\mathrm{MPa})\end{array}$ & 0.5 & 1 & 1.5 & 2 & - \\
\hline 5 & $\begin{array}{l}\text { Tensile strength normal to } \\
\text { bedjoints }\left(F_{\text {ty }}\right)(\mathrm{MPa})\end{array}$ & - & 0.15 & 0.25 & 0.35 & 0.45 \\
\hline 6 & $\begin{array}{c}\text { Tensile fracture energy along } \\
\text { bedjoints }\left(G_{f_{x}}\right)\end{array}$ & 0.0267 & 0.0533 & 0.08 & 0.1066 & - \\
\hline 7 & $\begin{array}{c}\text { Tensile fracture energy normal } \\
\text { to bedjoints }\left(G_{\mathrm{fy}}\right)\end{array}$ & - & 0.0042 & 0.007 & 0.0098 & 0.0126 \\
\hline 8 & $\begin{array}{l}\text { Compressive strength along } \\
\text { bedjoints }\left(\mathrm{F}_{\mathrm{cx}}\right)(\mathrm{MPa})\end{array}$ & - & 4.0 & 6.0 & 8.0 & - \\
\hline 9 & $\begin{array}{c}\text { Compressive strength normal to } \\
\text { bedjoints }\left(\mathrm{F}_{\mathrm{cy}}\right)(\mathrm{MPa})\end{array}$ & 4.0 & 6.0 & 8.0 & 10.0 & - \\
\hline 10 & $\begin{array}{l}\text { Compressive fracture energy } \\
\text { along bedjoints }\left(G_{f c x}\right)\end{array}$ & - & 5.0 & 7.5 & 10.0 & - \\
\hline 11 & $\begin{array}{l}\text { Compressive fracture energy } \\
\text { normal to bedjoints }\left(G_{\mathrm{fcy}}\right)\end{array}$ & 5.0 & 7.5 & 10.0 & 12.5 & - \\
\hline 12 & $\alpha$ & - & 1.0 & 1.35 & 1.5 & - \\
\hline 13 & $\boldsymbol{\beta}$ & -0.7 & -0.85 & -1.0 & -1.15 & -1.3 \\
\hline 14 & $\gamma$ & 3.0 & 5.0 & 7.5 & 10.0 & 12.5 \\
\hline
\end{tabular}

Table 4- Values of $a_{\min }$ and $b_{\min }$ for the minimum interaction curves of the walls with different aspect ratios

\begin{tabular}{|c|c|c|}
\hline $\boldsymbol{H} / \boldsymbol{L}$ & $\boldsymbol{a}_{\min }$ & $\boldsymbol{b}_{\min }$ \\
\hline $\mathbf{0 . 5}$ & 0.7 & 0.25 \\
\hline $\mathbf{1 . 0}$ & 0.6 & 0.35 \\
\hline $\mathbf{2 . 0}$ & 1.7 & 0.9 \\
\hline
\end{tabular}

Table 5- Coefficients of equation (12) for calculation of powers $a_{i}$ and $b_{i}$

\begin{tabular}{|c|c|c|c|c|c|c|c|c|c|c|c|}
\hline Power & $\mathbf{P}_{\mathbf{i}}$ & $\mathbf{x 1}$ & y1 & $\mathbf{x 2}$ & y2 & a1 & a2 & a3 & b1 & b2 & b3 \\
\hline \multirow{5}{*}{$\mathbf{a}$} & $\overline{\mathbf{E}_{\mathbf{x}}}$ & 3.50 & 4.00 & 2.10 & 2.50 & $1.66 \mathrm{E}-09$ & $2.723 \mathrm{E} 07$ & $-2.532 \mathrm{E} 06$ & 0.001 & $40.364 \mathrm{E} 06$ & $-7.922 \mathrm{E} 06$ \\
\hline & $\mathbf{E}_{\mathbf{y}}$ & 1.50 & 2.70 & 2.50 & 0.005 & $1.28 \mathrm{E}-07$ & 0.093 & 0.008 & $1.02 \mathrm{E}-11$ & 37.61 & -37.47 \\
\hline & $G$ & 1.50 & 5.00 & 0.70 & 0.10 & -0.05 & 17067 & $2.743 \mathrm{E} 05$ & $-7.39 \mathrm{E}+02$ & $1.666 \mathrm{E} 06$ & $-1.207 \mathrm{E} 06$ \\
\hline & $F_{t x}$ & 1.50 & 8.00 & 0.80 & 0.01 & -4.50 & 0.021 & 13.67 & -11.10 & 89.86 & -69.33 \\
\hline & $F_{\text {ty }}$ & 2.50 & 8.00 & 0.70 & 4.20 & $-9.74 \mathrm{E}+03$ & -124.3 & -822.4 & $-1.69 \mathrm{E}+03$ & -857.89 & -156.43 \\
\hline \multirow{2}{*}{$\mathbf{b}$} & $\mathbf{E}_{\mathbf{x}}$ & 0.05 & 2.00 & 0.01 & 0.01 & $-4.53 \mathrm{E}-03$ & $5.70 \mathrm{E}-04$ & $7.41 \mathrm{E}-03$ & -0.341 & 0.161 & 0.216 \\
\hline & $\mathbf{E}_{\mathbf{y}}$ & 2.50 & 2.50 & 3.50 & 3.50 & $6.99 \mathrm{E}-08$ & 0.01 & 19613 & $-1.46 \mathrm{E}-12$ & -3446 & 64950 \\
\hline
\end{tabular}




\begin{tabular}{|c|c|c|c|c|c|c|c|c|c|c|c|}
\hline & $\mathbf{G}$ & 2.00 & 2.00 & 2.80 & 0.01 & $1.33 \mathrm{E}-09$ & 0.01 & $3.32 \mathrm{E}-03$ & $4.57 \mathrm{E}-12$ & 0.001 & 0.04 \\
\cline { 2 - 12 } & $\mathbf{F}_{\mathbf{t x}}$ & 1.00 & 2.00 & 0.01 & 0.01 & $-2.84 \mathrm{E}-02$ & 0.01 & $5.837 \mathrm{E}-02$ & $-5.89 \mathrm{E}-01$ & 1.235 & -0.579 \\
\cline { 2 - 12 } & $\mathbf{F}_{\mathbf{t y}}$ & 1.50 & 1.00 & 4.00 & 1.00 & $4.78 \mathrm{E} 06$ & 0.01 & $6.25 \mathrm{E}+05$ & $13.104 \mathrm{E} 06$ & $-2.444 \mathrm{E} 06$ & $6.432 \mathrm{E} 06$ \\
\hline
\end{tabular}

Table 6- Material and geometrical properties of the three arbitrary walls Elastic parameters and aspect ratios

\begin{tabular}{|c|c|c|c|c|c|c|c|c|c|c|}
\hline & \multirow[b]{2}{*}{$\mathrm{H} / \mathrm{L}$} & \multicolumn{3}{|c|}{ Young's modulus (MPa) } & \multicolumn{3}{|c|}{ Poisson's ratio } & \multicolumn{3}{|c|}{ Shear modulus (MPa) } \\
\hline Wall & & $E_{x}$ & $\mathrm{E}_{\mathrm{y}}$ & $\mathrm{E}_{\mathrm{z}}$ & $v_{x y}$ & $v_{x z}$ & $v_{y z}$ & $\mathrm{G}_{\mathrm{xy}}$ & $\mathrm{G}_{\mathrm{xz}}$ & $\mathrm{G}_{y z}$ \\
\hline 1 & 2.0 & 24000 & 12000 & 24000 & 0.2 & 0.2 & 0.2 & 4800 & 4800 & 4800 \\
\hline 2 & 1.0 & 12000 & 6000 & 12000 & 0.2 & 0.2 & 0.2 & 2400 & 2400 & 2400 \\
\hline 3 & 0.5 & 8000 & 4000 & 8000 & 0.2 & 0.2 & 0.2 & 2400 & 2400 & 2400 \\
\hline
\end{tabular}

Inelastic parameters in tension regime

\begin{tabular}{|c|c|c|c|c|c|}
\hline Wall & $f_{t x}(\mathrm{MPa})$ & $f_{t y}(\mathrm{MPa})$ & $G_{f x}$ & $G_{f y}$ & $\alpha$ \\
\hline 1 & 1.0 & 0.15 & 0.0533 & 0.0042 & 1.35 \\
\hline 2 & 1.0 & 0.15 & 0.0533 & 0.0042 & 1.0 \\
\hline 3 & 1.5 & 0.15 & 0.08 & .0042 & 1.35 \\
\hline
\end{tabular}

Inelastic parameters in compression regime

\begin{tabular}{|c|c|c|c|c|c|c|c|}
\hline Wall & $f_{c x}(\mathrm{MPa})$ & $f_{c y}(\mathrm{MPa})$ & $G_{f c x}$ & $G_{f c y}$ & $\beta$ & $\gamma$ & $k_{c}$ \\
\hline 1 & 4.0 & 6.0 & 5.0 & 7.5 & -1.0 & 3.0 & 0.0005 \\
\hline 2 & 6.0 & 8.0 & 7.5 & 10.0 & -1.0 & 3.0 & 0.0005 \\
\hline 3 & 4.0 & 6.0 & 5.0 & 7.5 & -1.0 & 10.0 & 0.0005 \\
\hline
\end{tabular}




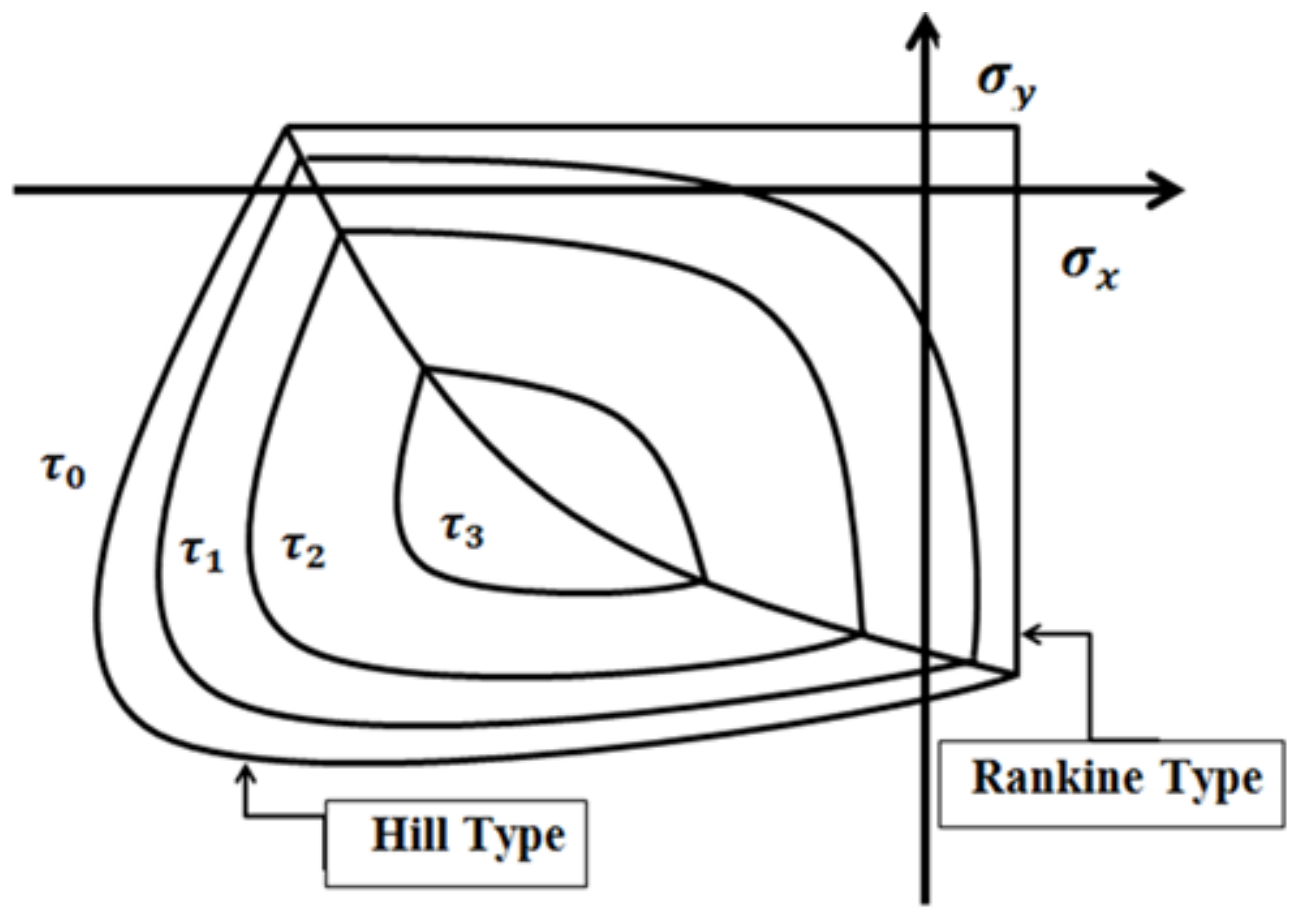

Fig. 1. The plane stress anisotropic yield criterion [22]

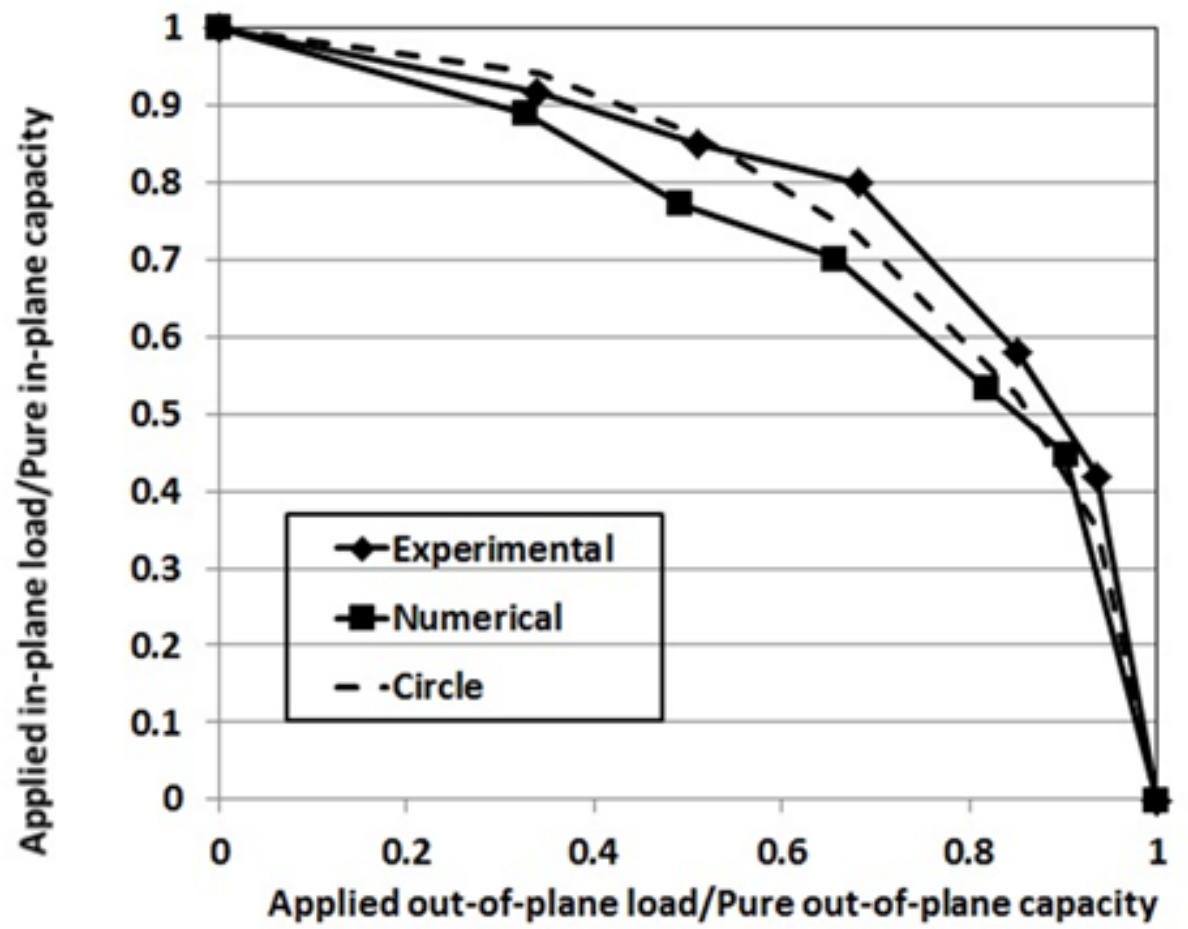

Fig. 2. Normalised in-plane, out-of-plane capacity interaction curves for the brick panels [14] 
(a)
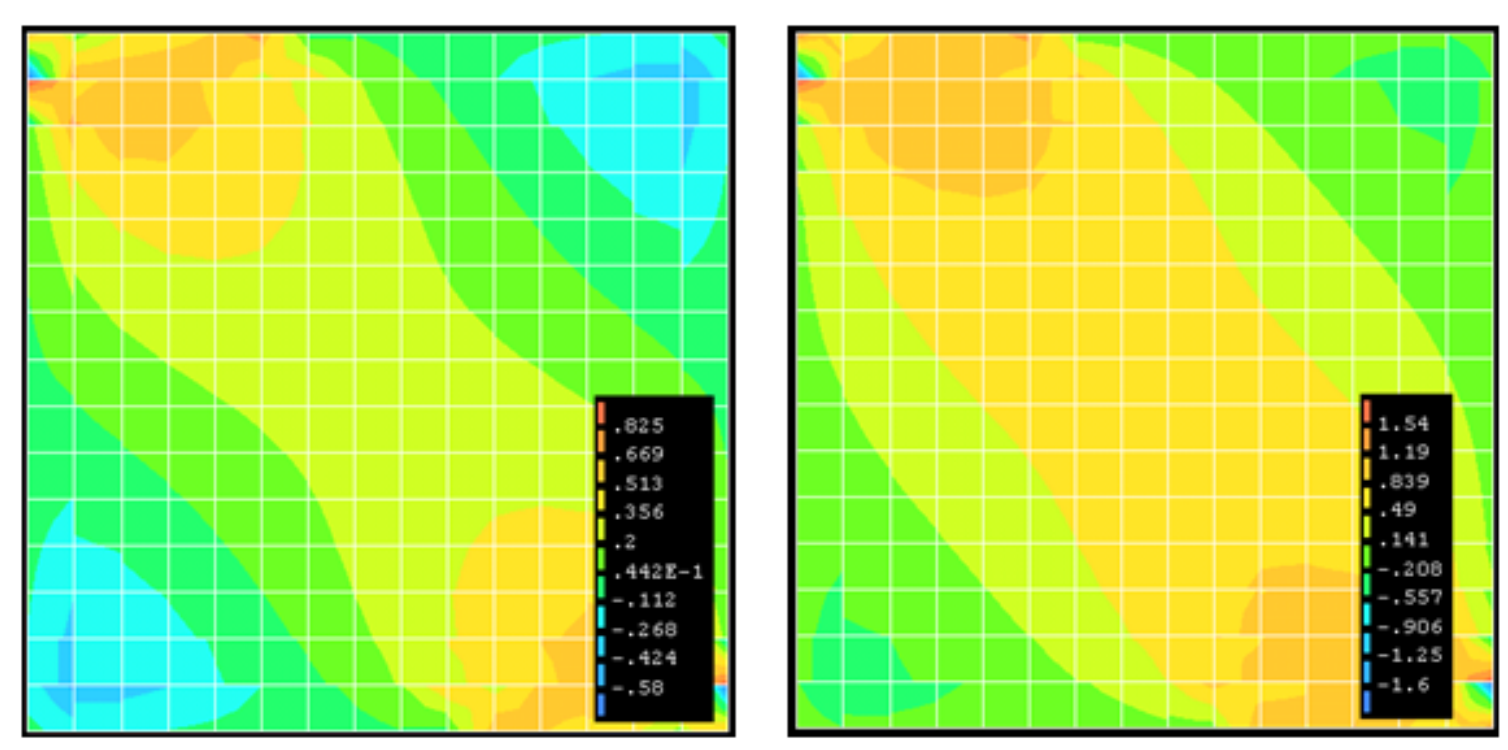

Fig. 3-Shear stress distribution in the brickwork of the square wall in the face subjected to tension, corresponding to an out-of-plane load/capacity ratio of 0.6 at (a) $50 \%$ of the ultimate capacity and (b) at failure.

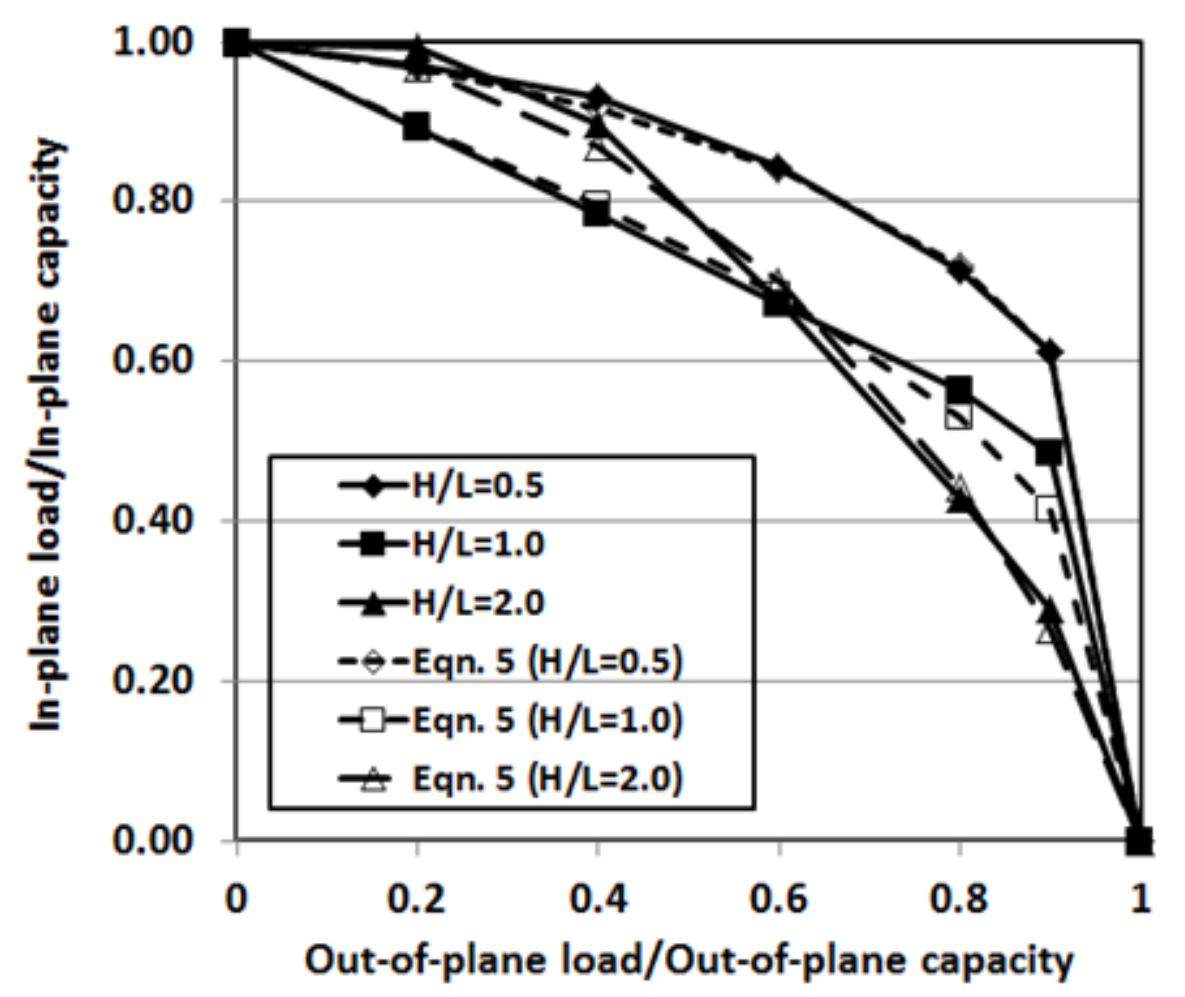

Fig. 4. Normalised numerical interaction curves for full scale walls with three different aspect ratios 


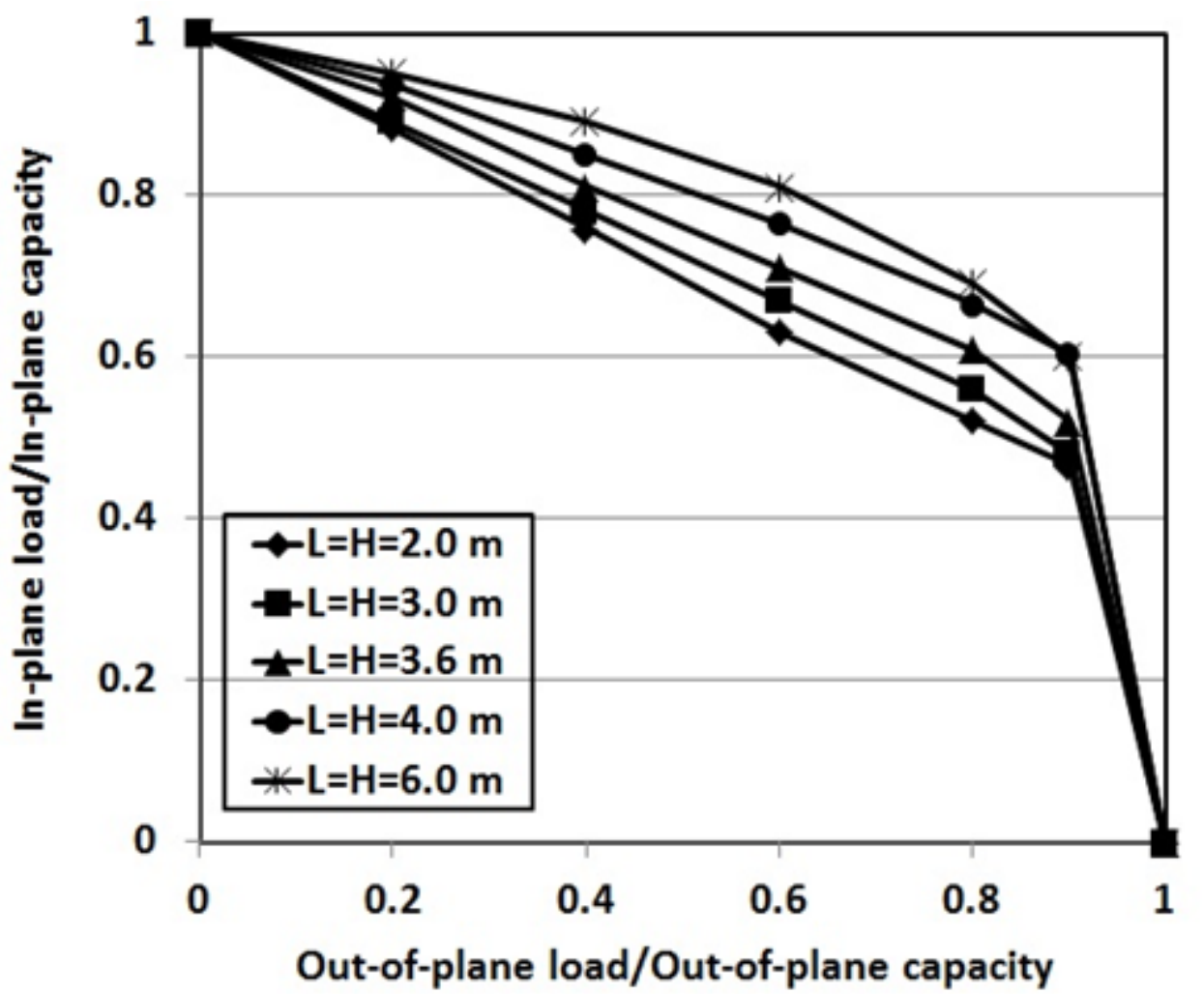

Fig. 5. Normalised calculated interaction curves for square walls of different sizes 
(a)

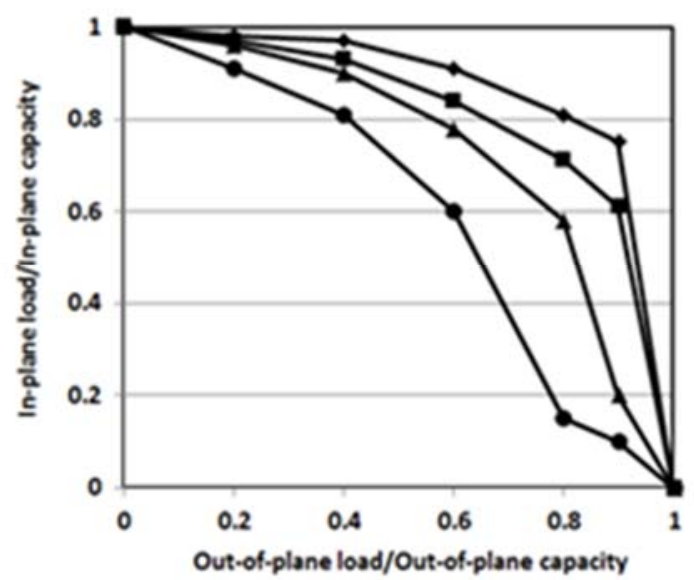

(c)

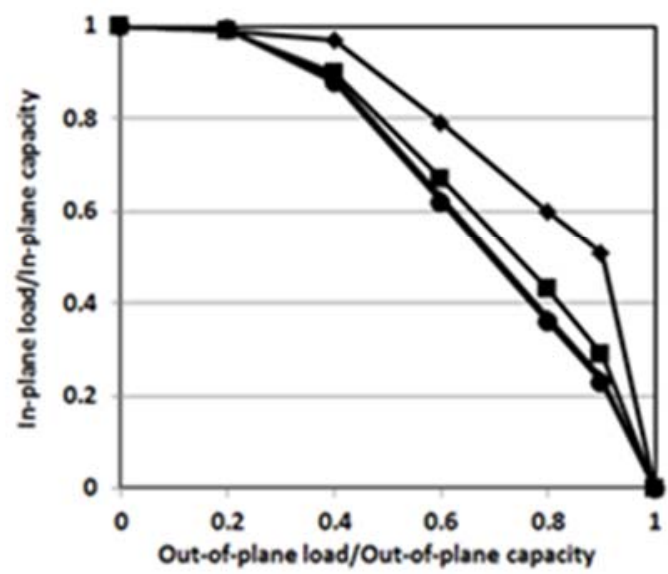

(b)

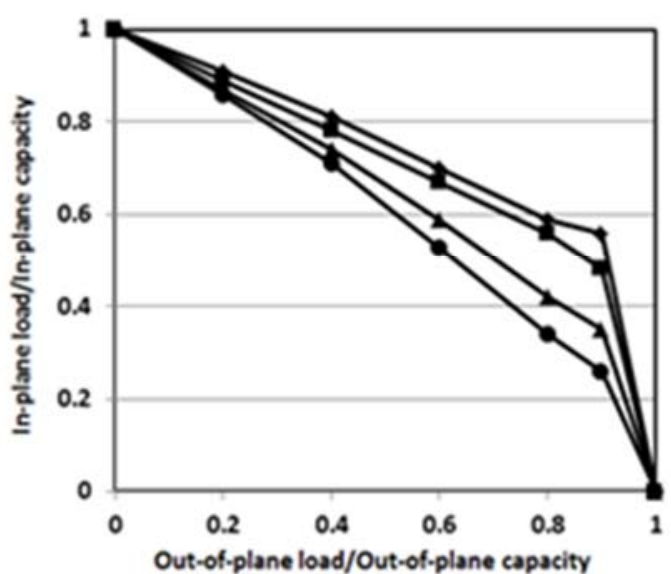

$$
\begin{aligned}
& \leftarrow E x=8000 \\
& -E x=12000 \\
& \text { †Ex }=16000 \\
& \leftarrow E x=24000
\end{aligned}
$$

Fig. 6- The effects of modulus of elasticity along bed joints $\left(E_{x}\right)$ on the capacity interaction curves of walls with (a) $\mathrm{H} / \mathrm{L}=0.5$, (b) $\mathrm{H} / \mathrm{L}=1.0$ and (c) $\mathrm{H} / \mathrm{L}=2.0$ 
(a)

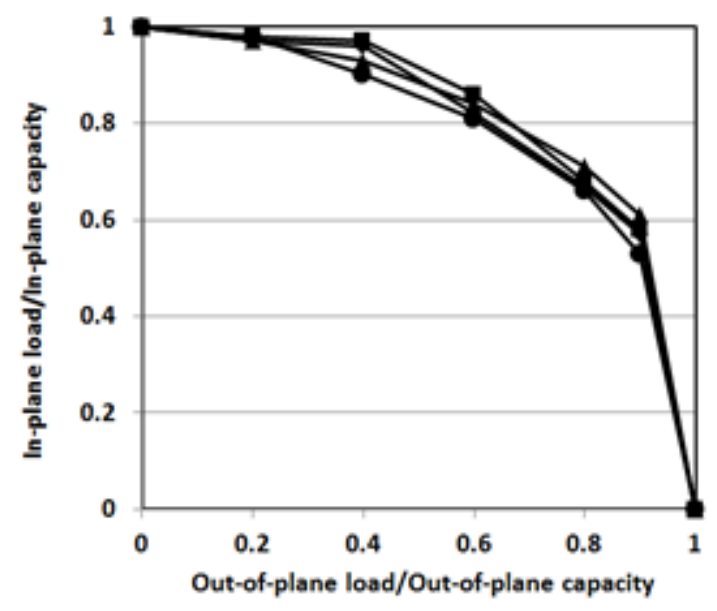

(c)

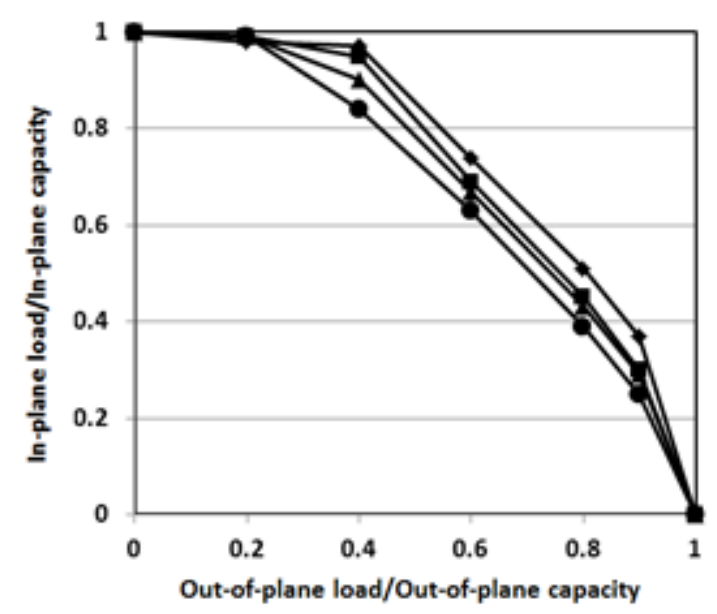

(b)

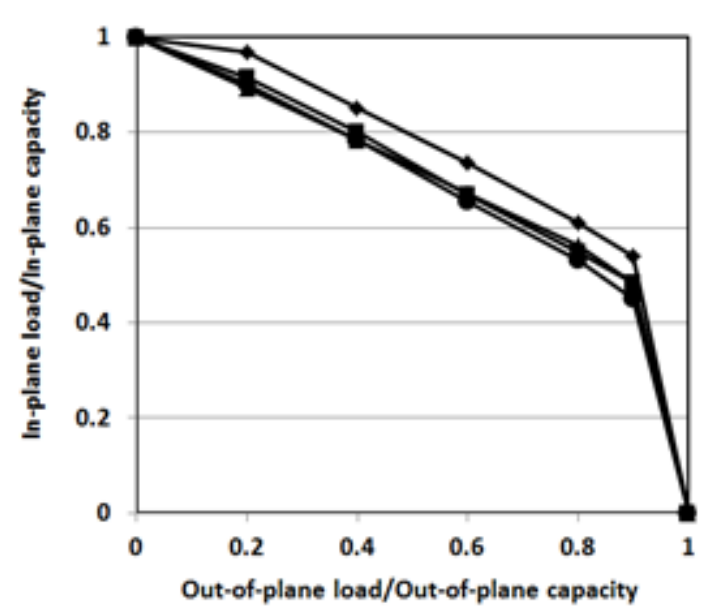

Fig. 7- The effects of modulus of elasticity normal to bed joints $\left(E_{y}\right)$ on the capacity interaction curves of walls with (a) $\mathrm{H} / \mathrm{L}=0.5$, (b) $\mathrm{H} / \mathrm{L}=1.0$ and (c) $\mathrm{H} / \mathrm{L}=2.0$ 
(a)

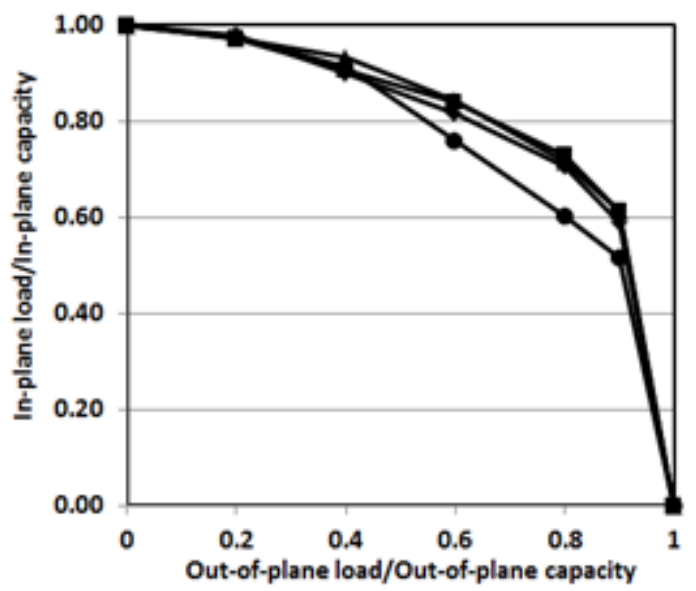

(c)

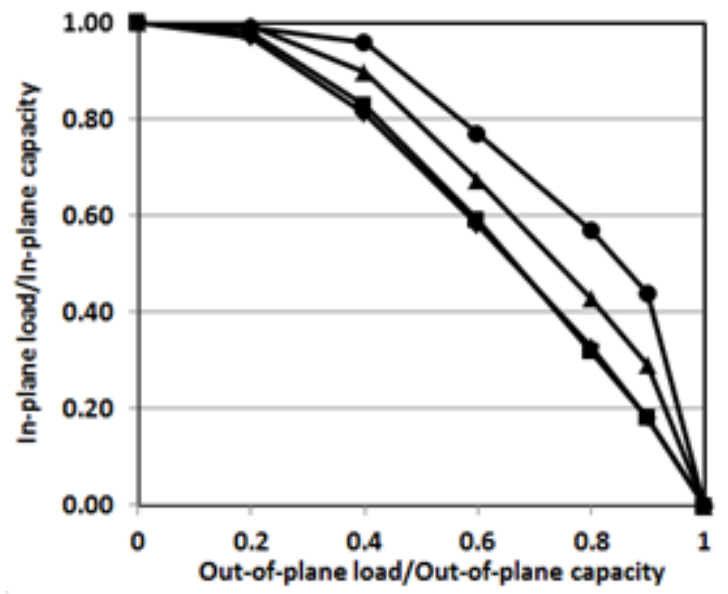

(b)

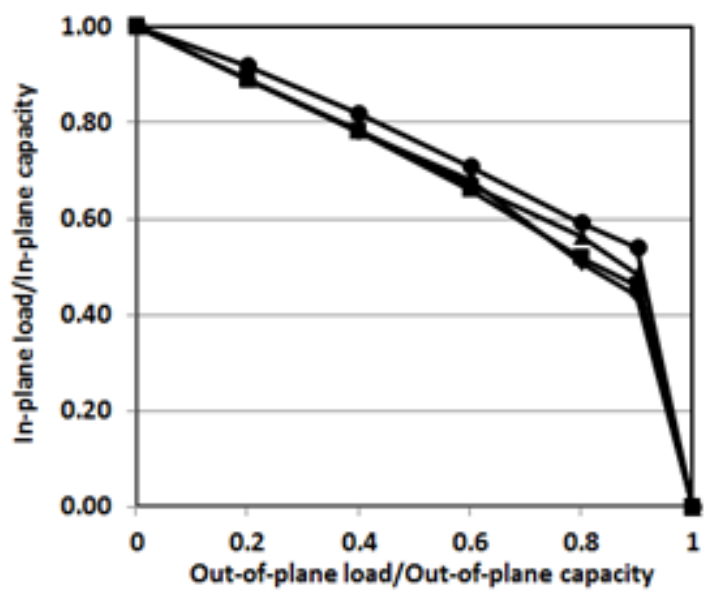

Fig. 8- The effects of shear modulus $(G)$ on the capacity interaction curves of walls with (a) $\mathrm{H} / \mathrm{L}=0.5$, (b) $\mathrm{H} / \mathrm{L}=1.0$ and (c) $\mathrm{H} / \mathrm{L}=2.0$ 
(a)

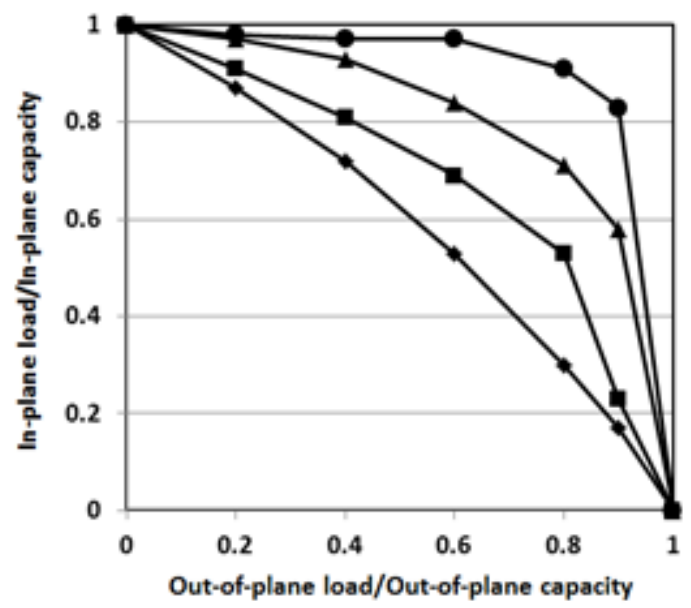

(c)

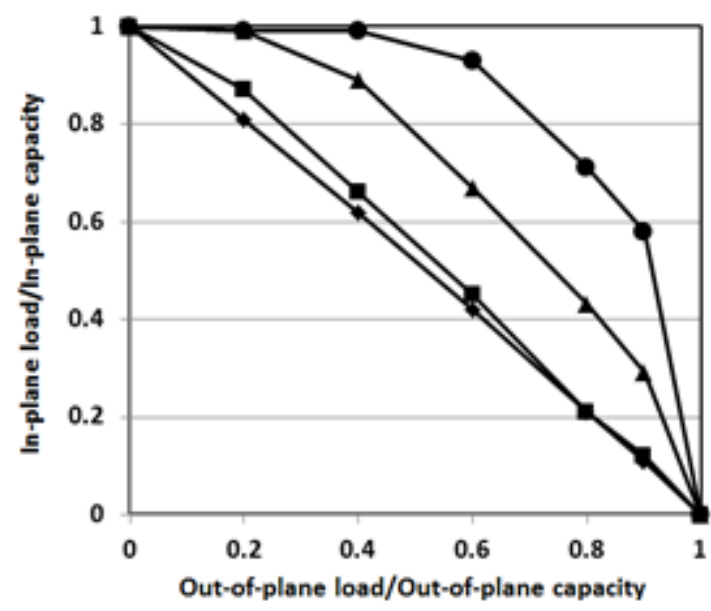

(b)

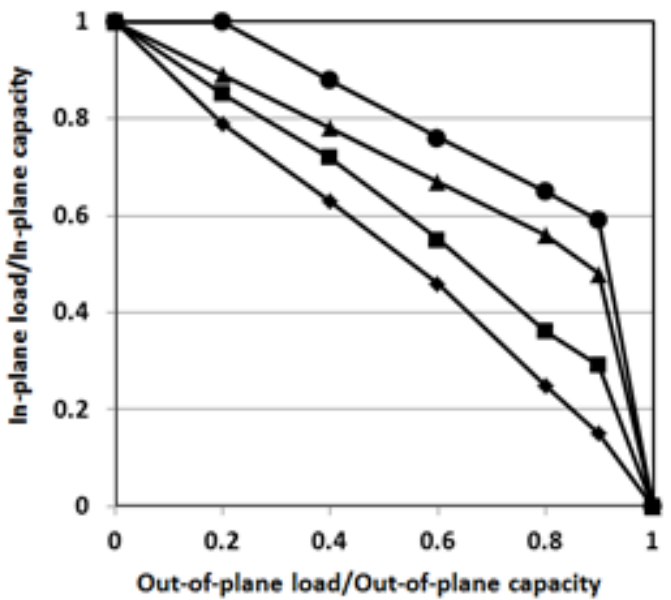

$\leadsto \mathrm{ftx}=0.5$

$+\mathrm{ftx}=\mathbf{1 . 0}$

$\pm \mathrm{ftx}=1.5$

$-\mathrm{ftx}=2.0$

Fig. 9- The effects of tensile strength along bedjoints $\left(f_{t x}\right)$ on the capacity interaction curves of walls with (a) $\mathrm{H} / \mathrm{L}=0.5$, (b) $\mathrm{H} / \mathrm{L}=1.0$ and (c) $\mathrm{H} / \mathrm{L}=2.0$ 
(a)

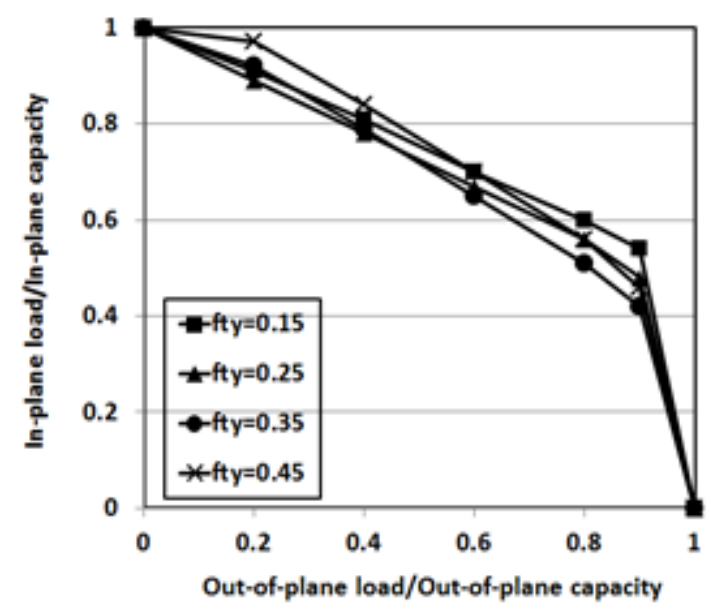

(c)

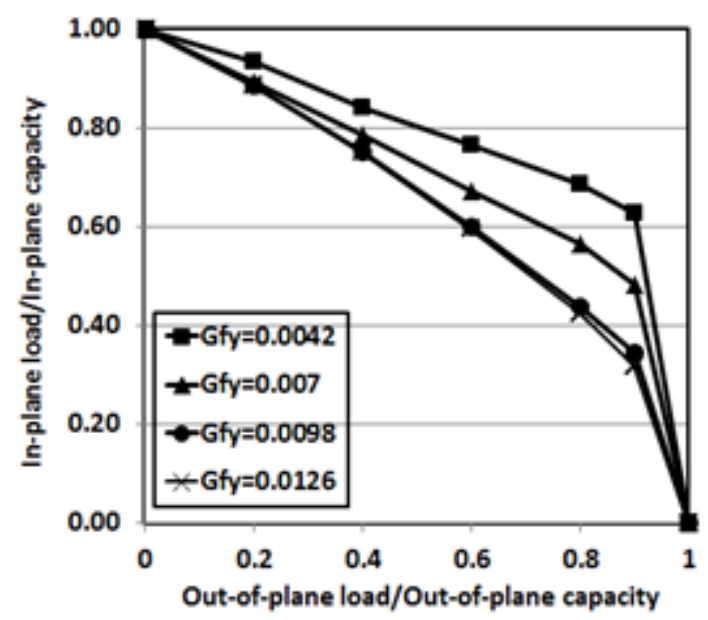

(b)

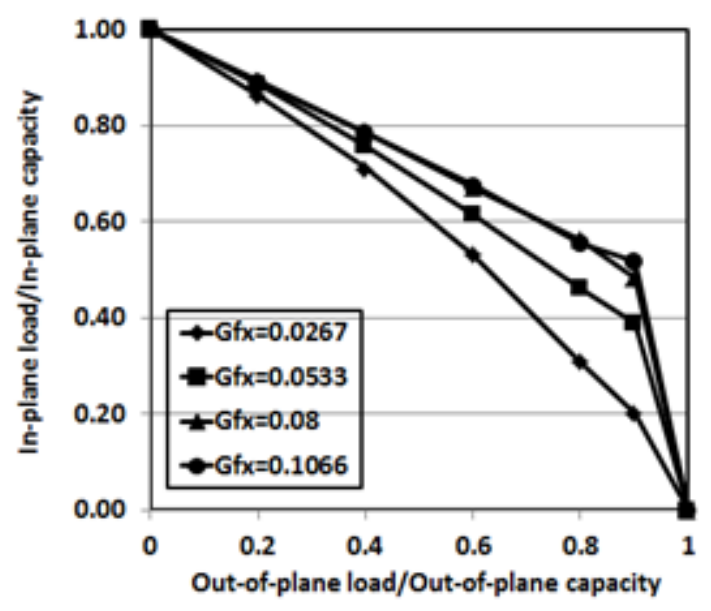

(d)

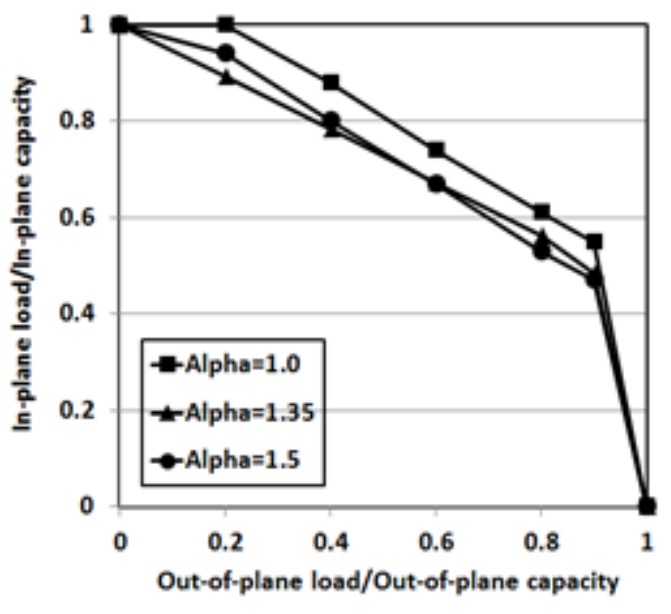

Fig. 10- Interaction curves for the square wall $(\mathrm{H} / \mathrm{L}=1.0)$, for different values of (a) $f_{t y},(\mathrm{~b})$ $G_{t x},(\mathrm{c}) G_{t y}$ and (d) $\alpha$ 
(a)

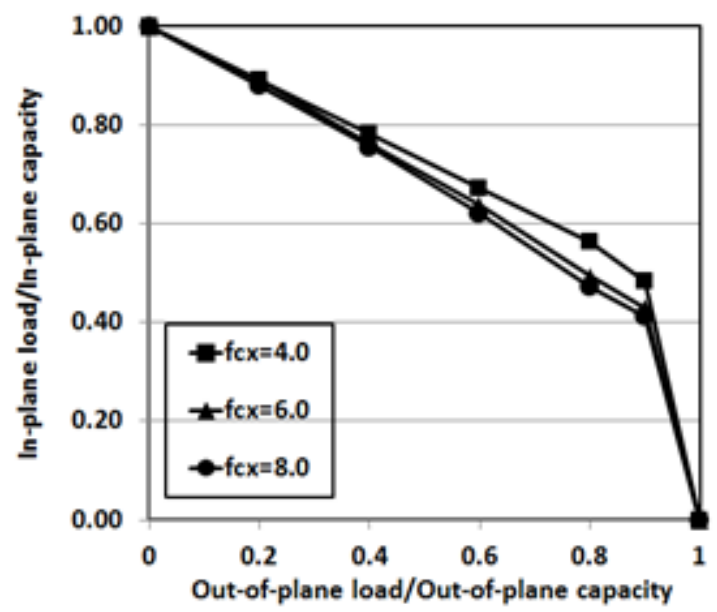

(c)

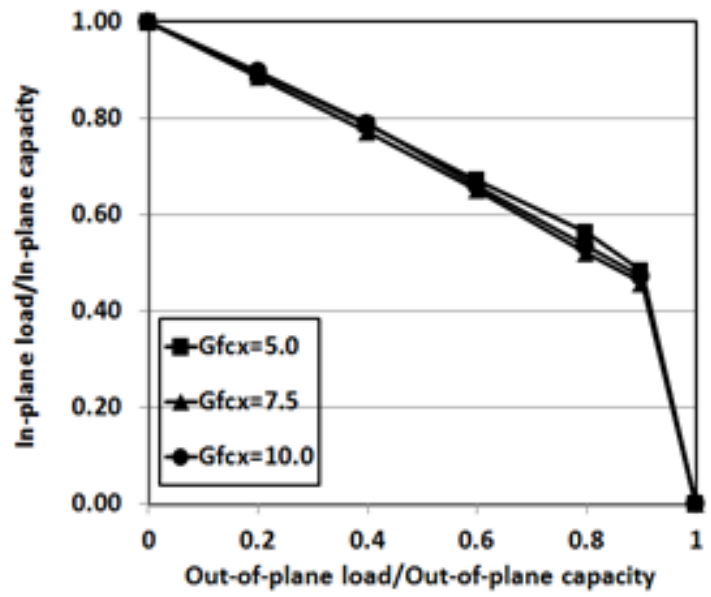

(b)

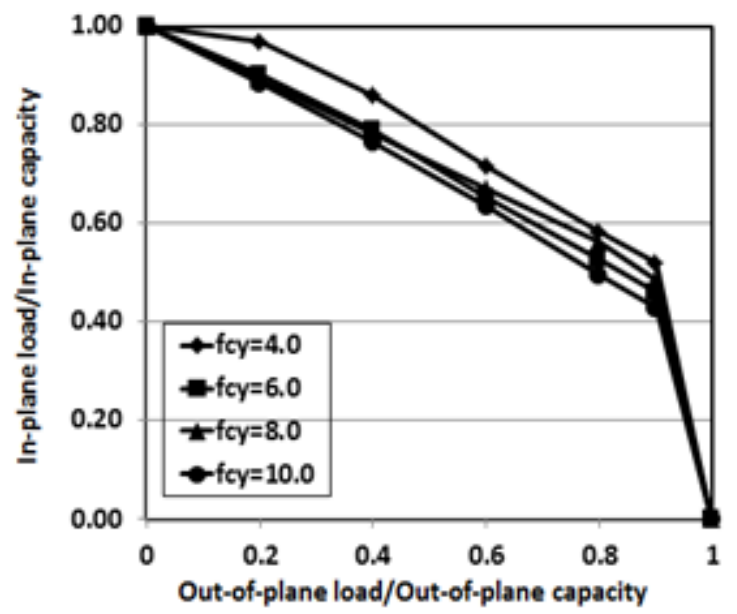

(d)

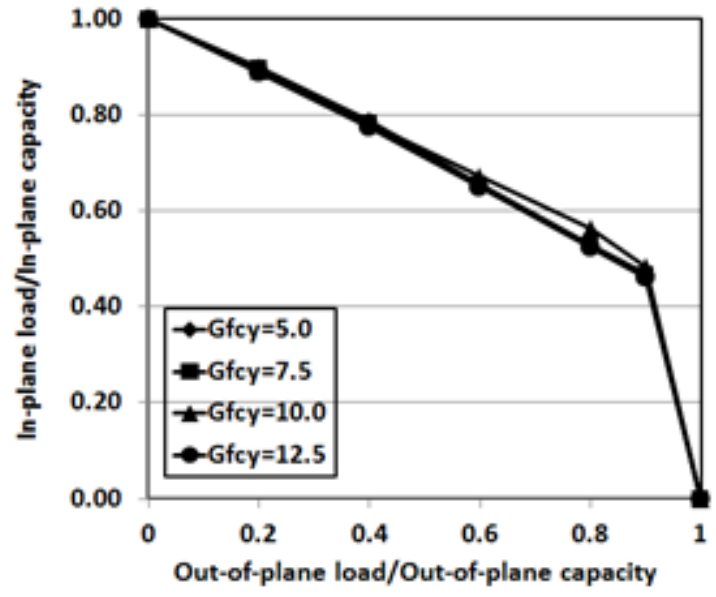

Fig. 11 - Interaction curves for different values of (a) $f_{c x}$, (b) $f_{c y}$, (c) $G_{f c x}$ and (d) $G_{f c y}$ 
(a)

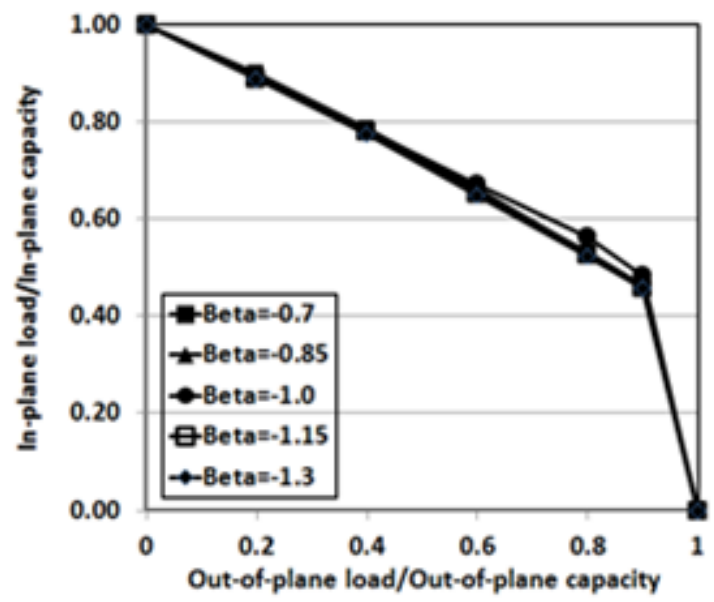

(b)

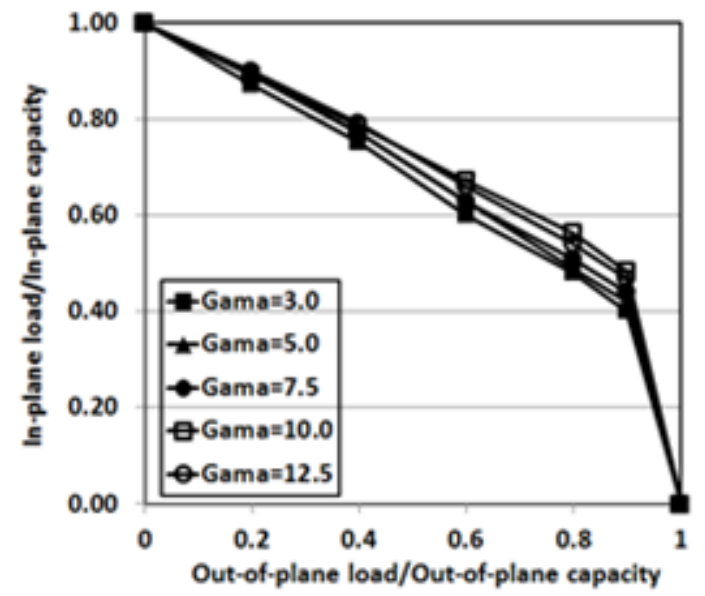

Fig. 12- Interaction curves for different values of (a) $\beta$ and (b) $\gamma$.

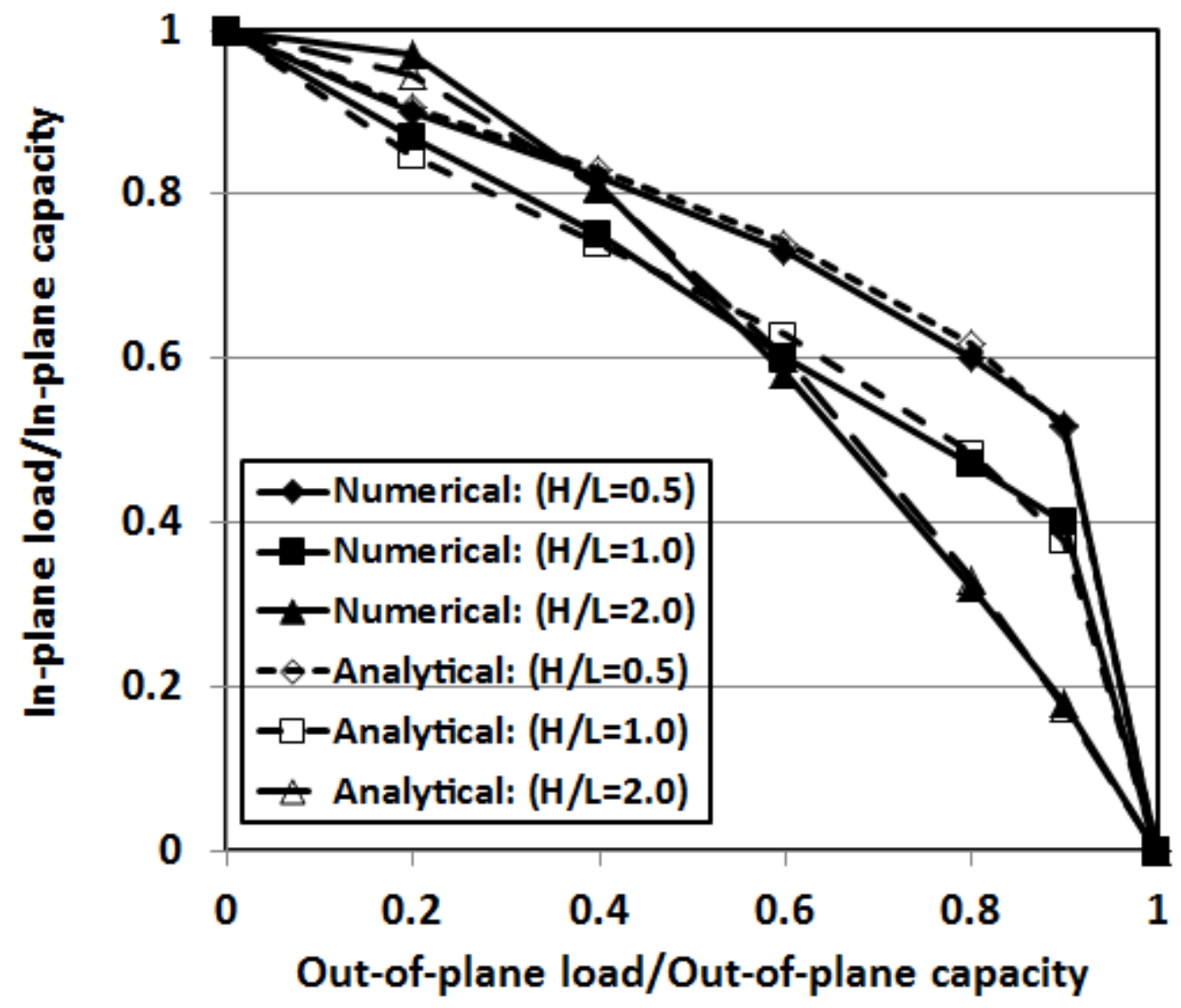

Fig. 13- The minimum of the numerical and analytical interaction curves obtained with secondary material properties 


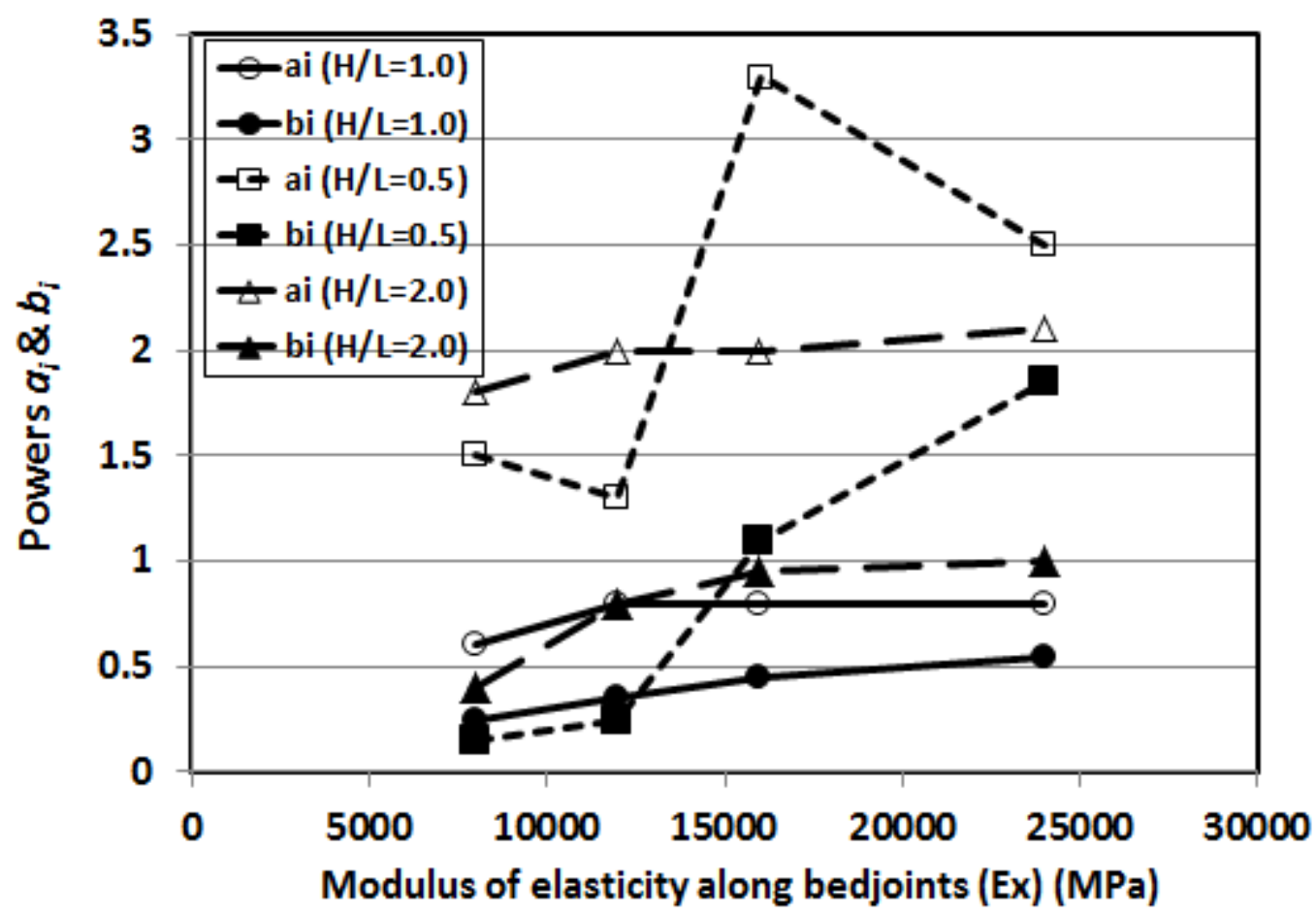

Fig. 14- Powers $a_{i}$ and $b_{i}$ for different values of modulus of elasticity along bedjoints

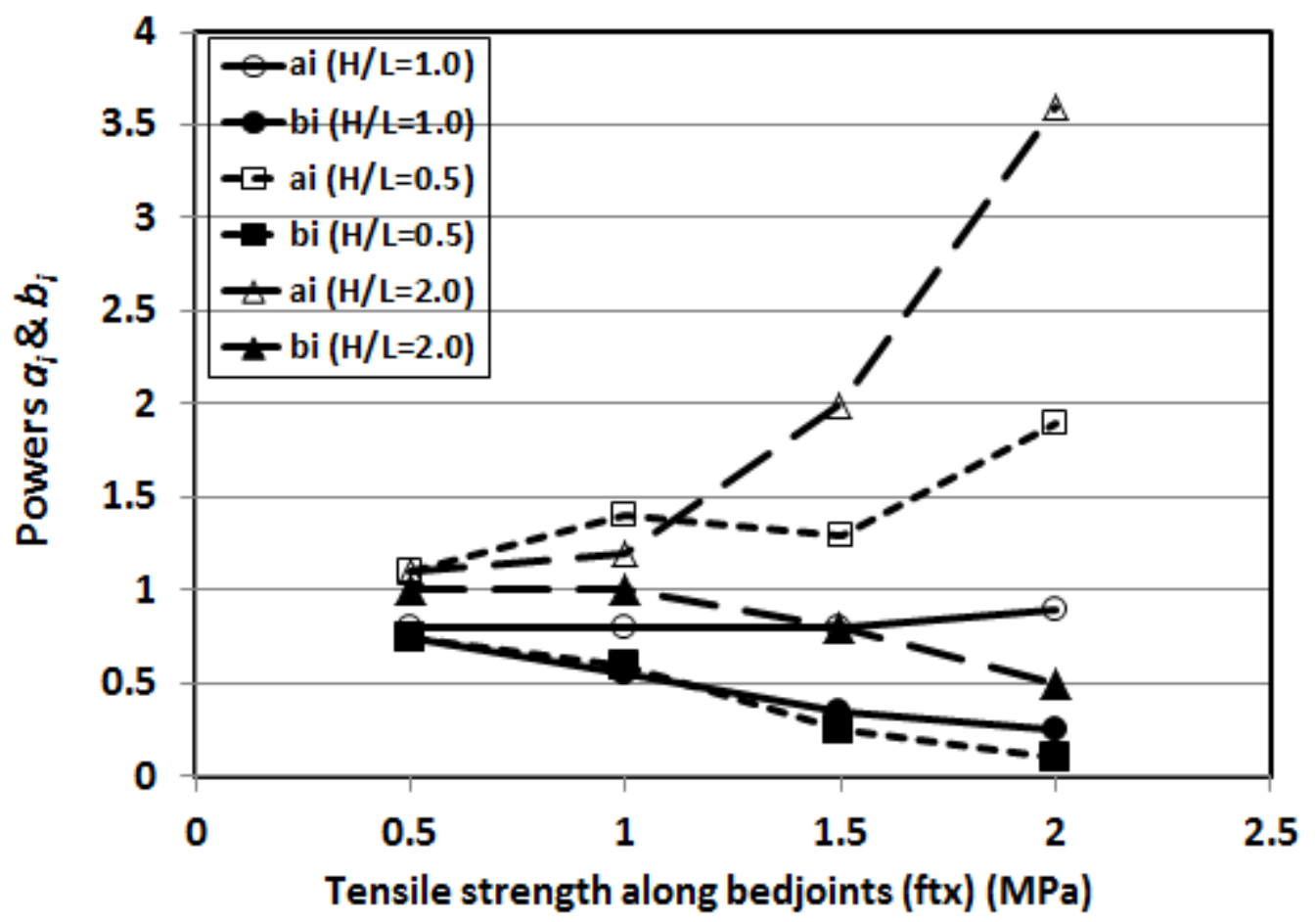

Fig. 15- Powers $a_{i}$ and $b_{i}$ for different values of tensile strength along bedjoints 


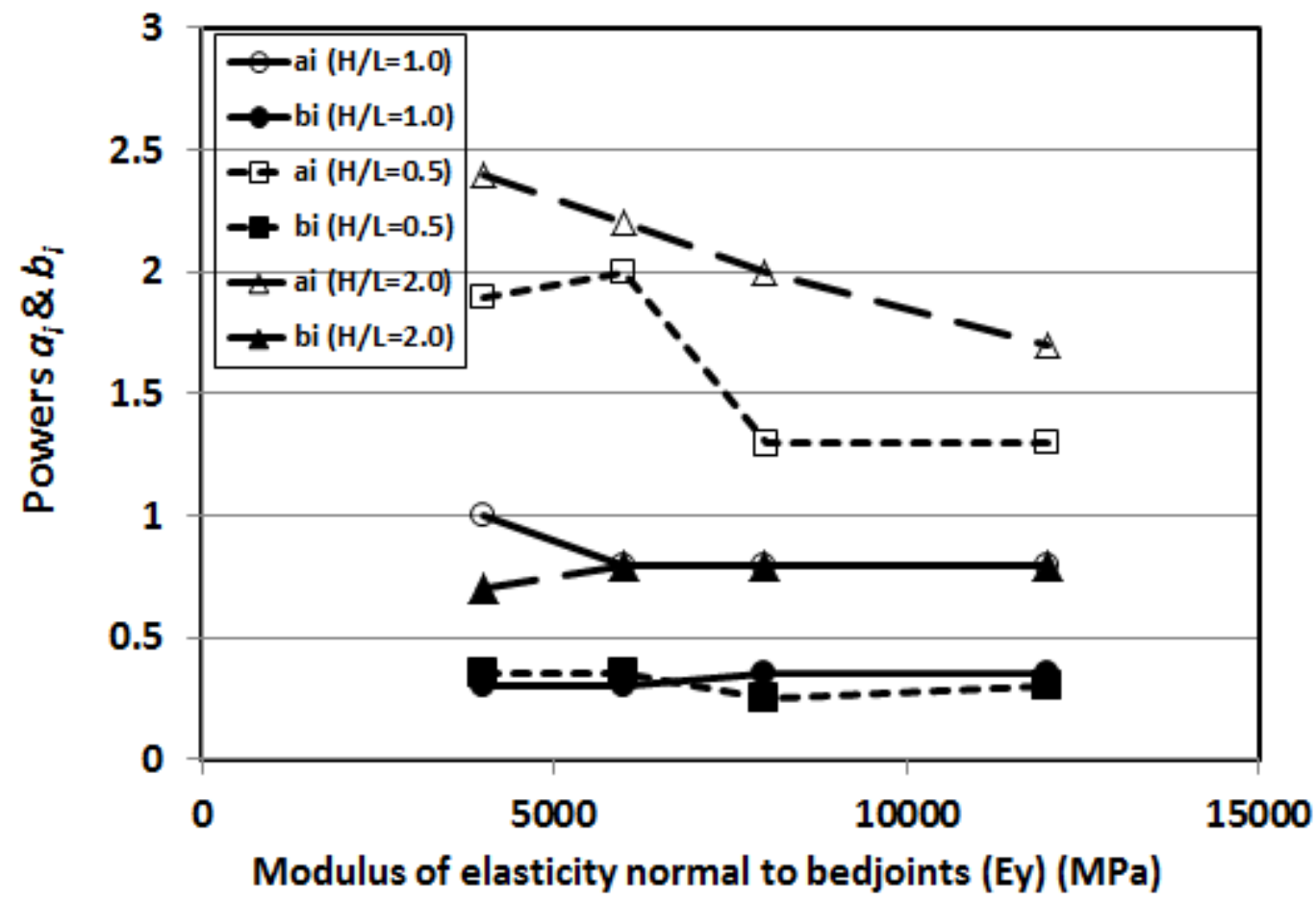

Fig. 16- Powers $a_{i}$ and $b_{i}$ for different values of modulus of elasticity normal to bedjoints

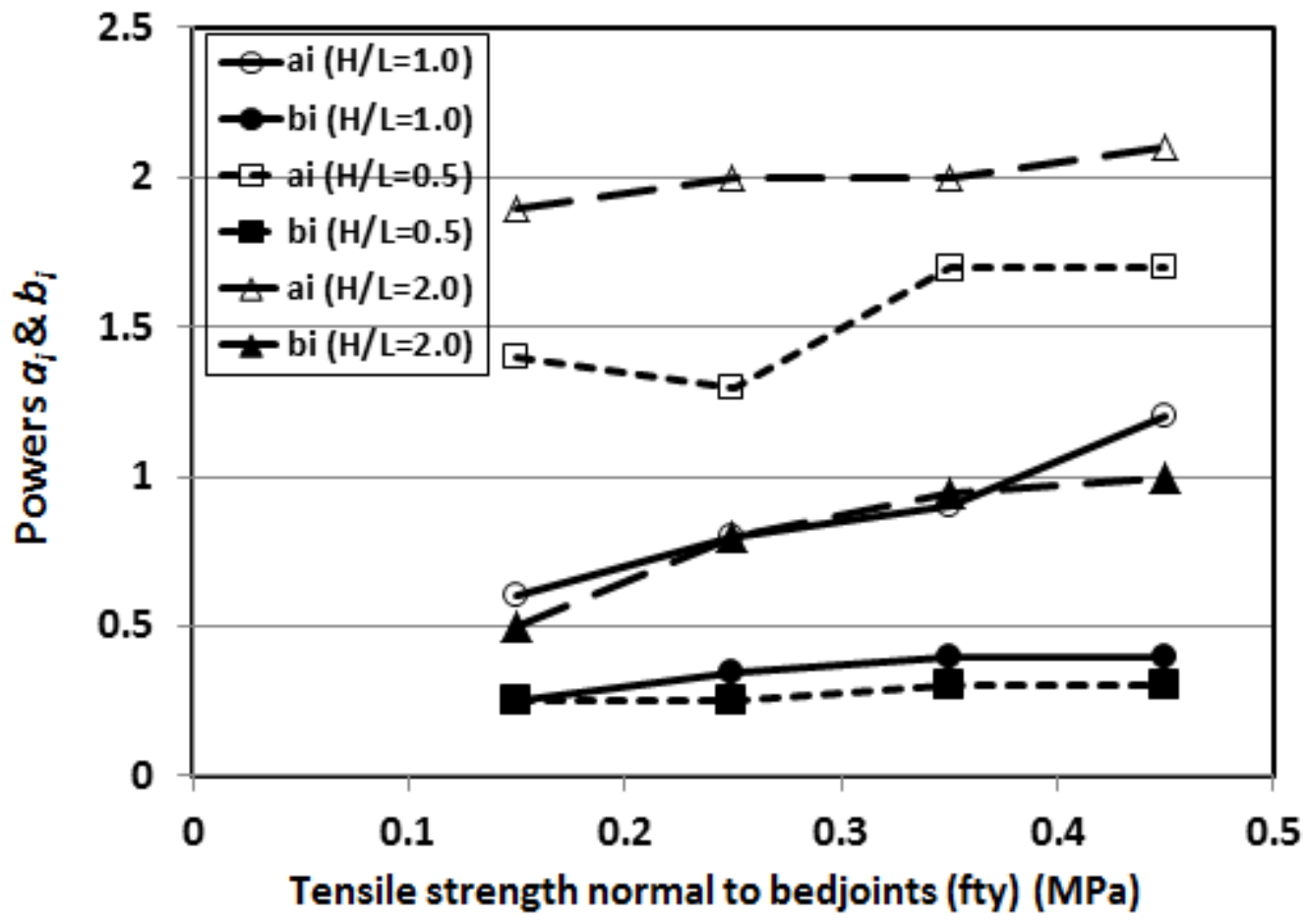

Fig. 17- Powers $a_{i}$ and $b_{i}$ for different values of tensile strength normal to bedjoints 


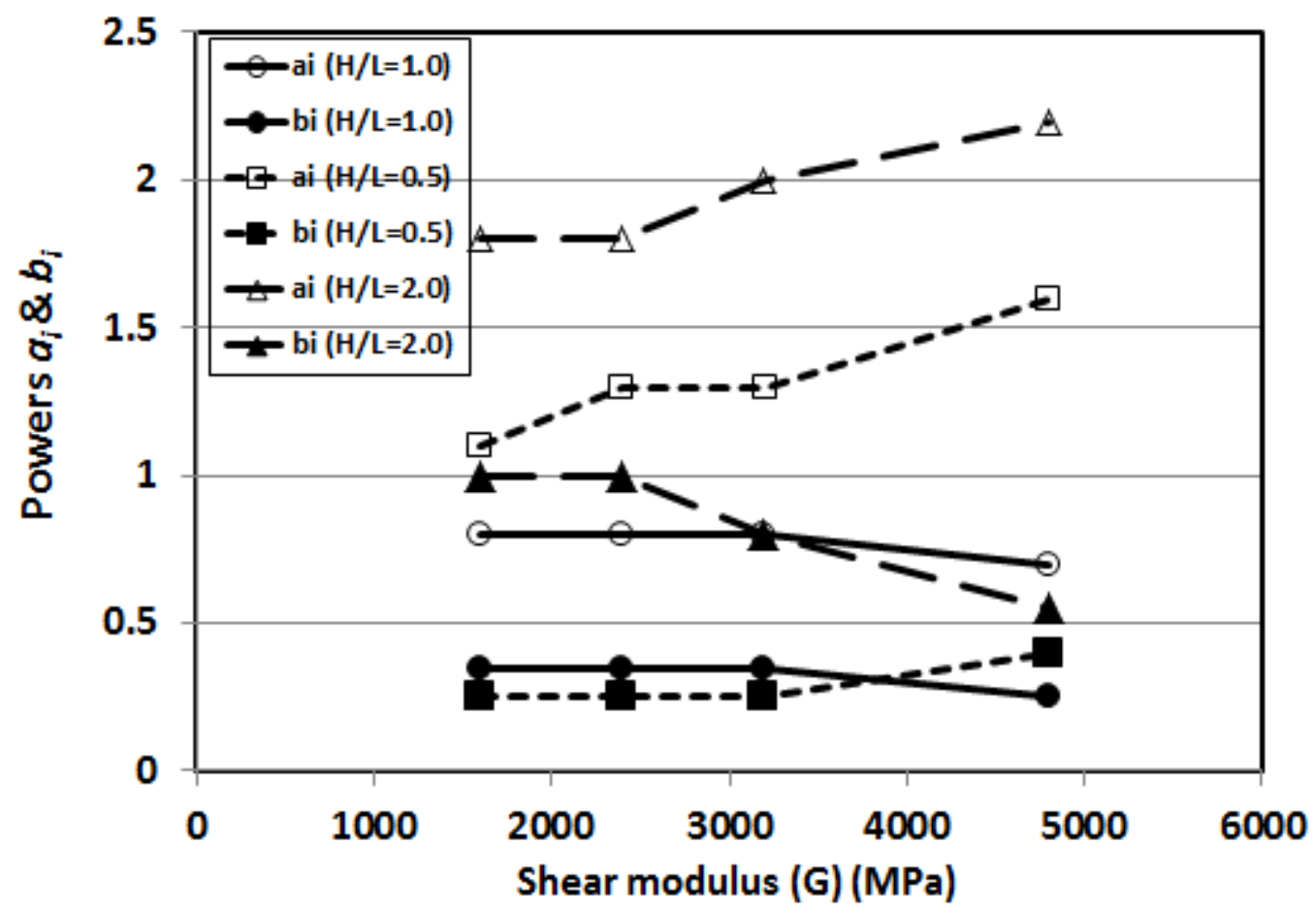

Fig. 18- Powers $a_{i}$ and $b_{i}$ for different values of shear modulus 


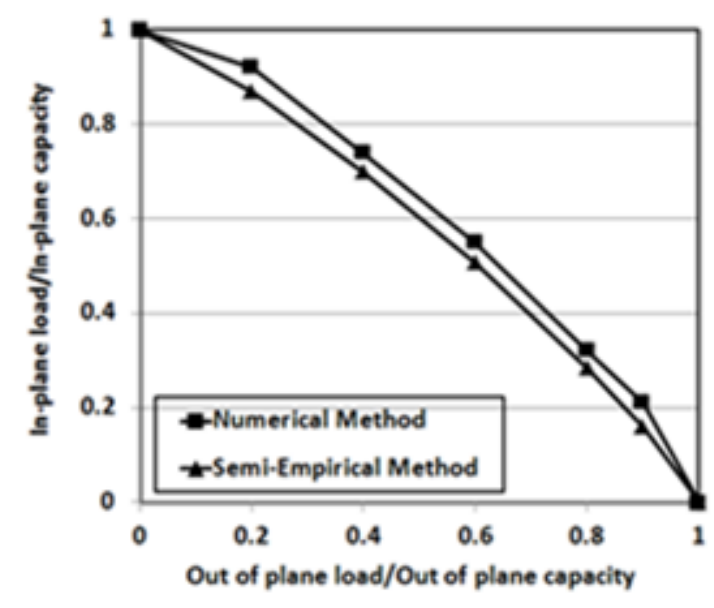

Wall \# 1

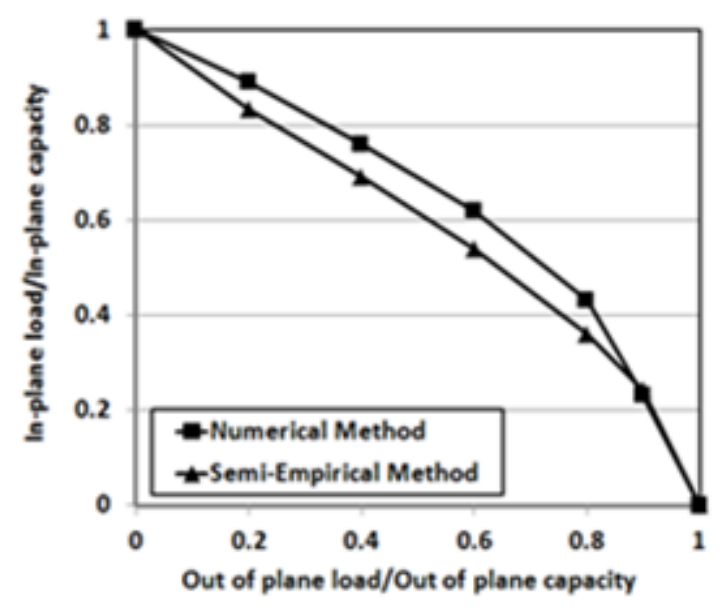

Wall \# 2

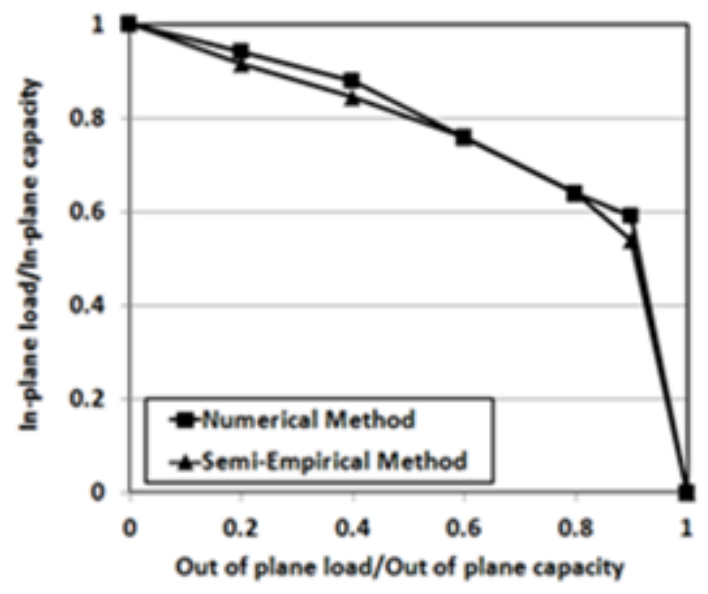

Wall \# 3

Fig. 19- Comparison of interaction curves obtained with numerical and semi-empirical methods 